\title{
THE OPTIMAL SCOPE OF THE ROYALTY BASE IN PATENT UCENSING
}

\author{
Gerard Llobet and Jorge Padilla
}

CEMFI Working Paper No. 1409

December 2014

CEMFI

Casado del Alisal 5; 28014 Madrid

Tel. (34) 914290551 Fax (34) 914291056

Internet: www.cemfi.es

The ideas and opinions in this paper, as well as any errors, are exclusively the authors'. Financial support from Qualcomm is gratefully acknowledged. 
CEMFI Working Paper 1409

December 2014

\title{
THE OPTIMAL SCOPE OF THE ROYALTY BASE IN PATENT UCENSING
}

\begin{abstract}
There is considerable controversy about the relative merits of the apportionment rule (which results in per-unit royalties) and the entire market value rule (which results in ad-valorem royalties) as ways to determine the scope of the royalty base in licensing negotiations and disputes. This paper analyzes the welfare implication of the two rules abstracting from implementation and practicability considerations. We show that advalorem royalties tend to lead to lower prices, particularly in the context of successive monopolies. They benefit upstream producers but not necessarily hurt downstream producers. When we endogenize the investment decisions, we show that a sufficient condition for ad-valorem royalties to improve social welfare is that enticing more upstream investment is optimal or when multiple innovators contribute complementary technologies. Our findings contribute to explain why most licensing contracts include royalties based on the value of sales.
\end{abstract}

JEL Codes: L15, L24, O31, O34.

Keywords: Intellectual property, standard setting organizations, patent licensing, R\&D investment.

Gerard Llobet

CEMFI

llobet@cemfi.es
Jorge Padilla

Compass Lexecon

JPadilla@compasslexecon.com 


\section{Introduction}

The licensing of a patented technology is one of the most important sources of revenue for many innovators, particularly, when they do not participate in the production in the final market. A licensing contract typically includes a royalty payment that comprises two components: a royalty rate and a royalty base. Most attention in the economic literature has been devoted to the optimal determination of the royalty rate. Much less work has been done in studying the scope of the royalty base. This scope can be determined in two principal ways. One option is the value of the components of the infringing product that incorporate the patented technology. This is the so-called apportionment rule. Alternatively, the scope of the royalty base can be given by the value of the sales of the entire product - the entire market value rule. These two rules give raise to the usage of per-unit royalty rates (a constant payment based on the units sold) and ad-valorem royalty rates (a payment comprising a percentage of the value of the sales of the product), respectively.

There is wide agreement among practitioners and legal scholars that the "entire market value rule" is appropriate when the components incorporating the patented technology drive the demand for the product. There is also wide agreement that in a perfect world with rational judges and juries and in the absence of reporting and monitoring frictions, both rules would produce the same payment outcomes even if the components incorporating the patented technology do not drive the demand for the product The argument is that in a frictionless world "the individual elements of a royalty payment are irrelevant in isolation, as one variable [i.e. the royalty rate] can adjust with the other [i.e. the royalty base]." ${ }^{2}$

\footnotetext{
${ }^{1}$ As stated by the U.S. Court of Appeals to the Federal Circuit (CAFC) "there is nothing inherently wrong with using the market value for the entire product for the infringing component or feature, so long as the multiplier accounts for the proportion of the base represented by the infringing component or feature." Lucent Techs., Inc. v. Gateway, Inc., 580 F. 3d 1301, 1338-39 (Fed. Cir. 2009).

${ }^{2}$ See Geradin and Layne-Farrar (2011).
} 
In contrast, there is considerable controversy about the appropriate rule for the determination of the scope of the royalty base when the components incorporating the patented technology do not drive the demand for the product and there is bounded rationality and/or asymmetries of information. In those circumstances, some scholars support the apportionment rule because they fear that a royalty base that is broader than the value of the components incorporating the technology may mislead judges or juries into granting excessively high royalty payments (Love, 2007). They are concerned therefore that the entire market value rule will over-compensate patent holders. These authors believe that the only way to ensure that royalty payments are proportionate to the contribution of the patented technology to the infringing product is to limit the scope of the royalty base so that it does not include any value attributable to the infringer or third parties.

On the other end of the spectrum, those that support the entire market value rule argue that the apportionment rule is too difficult to apply in practice. They claim that the economic value added to a product by a patented component is often greater than the value of the component alone and, hence, the apportionment rule will likely underreward innovation when the component at issue enables other components even if is not the sole driver of demand. They also argue that it is difficult to value the various components that define a product - especially when the valuation exercise concerns complex products with multiple interrelated technologies - and, hence, that apportionment can be a difficult and subjective task (Sherry and Teece, 1999). The entire market value rule may prove especially apt in the context of portfolio licensing where licensors hold patents covering different components of the infringing product. Finally, those supporting the entire market value rule explain that ad-valorem royalties - i.e. royalty payments using the entire market value of the product as base - are easier to implement in practice because the value of sales of a product is observable in public documents, whereas per-unit 
royalties require the direct monitoring of the number of units sold (and hence the number of components used) $!^{3}$

In this paper we do not revisit the debate about the practicality of the base selected to calculate royalty payments. We focus instead on the consensus that in a perfect world with no monitoring frictions or boundedly rational judges and juries the apportionment rule (i.e. per-unit royalties) would yield the same market outcomes than the entire market value rule (i.e. ad-valorem royalties). We show that such a consensus is flawed. We find that in most circumstances, ad-valorem royalties yield market outcomes that are welfare superior to those resulting from the use of per-unit royalties. Or, in other words, we find that even leaving aside implementation issues, the entire market value rule is better for most market participants, and in particular for the consumers of the products embedding the patented technology, than the apportionment rule.

In order to compare the welfare implications of the apportionment and entire market value rules, we contribute to the existing literature on licensing contracts. This literature has typically focused on the usage of combinations of fixed fees and per-unit royalties. Surprisingly, very little attention has been paid to ad-valorem royalties. $4^{4}$ This is a striking fact if we compare it with the existing empirical evidence. In a sample of 278 contracts, Bousquet et al. (1998) shows that while 225 include royalties only in 9 of them these royalties were paid per-unit.

We develop a model of innovation and subsequent pricing decisions in order to under-

\footnotetext{
${ }^{3}$ See Geradin and Layne-Farrar $(2011)$. While the apportionment rule links the scope of the royalty base to the value of the components covered by the patented technology, it is easy to demonstrate that royalties determined under that rule are mathematically equivalent to per-unit royalty rates since their effect is to increase the marginal cost of production of the implementer(s).

${ }^{4}$ In vertical relationships, papers like Kamien and Tauman $(1986)$ have shown that fixed fees are superior to per-unit royalties even when there are several downstream producers to which the technology can be licensed. Of course, the previous results do not hold when we consider market frictions. Papers like Hernández-Murillo and Llobet (2006) have shown that royalties can be optimal when asymmetric information considerations are included in the model.

In contrast, there is an extensive and classical literature comparing ad-valorem versus per-unit taxes (Suits and Musgrave, 1953), leading to insights related to some of the results we discuss here.
} 
stand the implications of the different kinds of royalties. This model includes a vertical relationship between innovators, upstream players that create an innovation, and producers, downstream players that implement these innovations and develop products for the final market. In this context we show that per-unit and ad-valorem royalties lead to different outcomes and different ways in which profits are split between upstream innovators and downstream producers. These different profits feed back into the incentives for firms to innovate and develop new products. Through the inclusion of a very stylized research and development stage to a model of technology transfer we can also assess the welfare effects on an industry of mandating the use of per-unit or ad-valorem royalties.

The main results indicate that ad-valorem royalties often lead to higher social welfare, and this could explain their prevalence in practice. In order to understand this result it is useful to separate the effects of the royalties in the research and development and the pricing stage. We start with the latter.

In the main part of the paper we analyze the decision of an upstream monopolist that licenses its technology to a pure downstream player. Abstracting from the incentives to innovate - that is, assuming that all innovation and development has been successfully carried out - we show that ad-valorem royalties favor the upstream producer whereas the opposite is true for per-unit royalties. Furthermore, the resulting price in the final market is never higher under ad-valorem royalties. The reason is that ad-valorem royalties impose a royalty tax on the downstream mark-up, reducing the profitability of price increases. As a result, they typically make the double-marginalization problem less severe, generating lower distortions in the final market. Only under an isoelastic demand function prices are identical under both licensing schemes. Even in that case, however, ad-valorem royalties lead to lower prices when we allow for an balanced allocation of bargaining power among the two firms.

Once we introduce several upstream innovators that provide complementary technolo- 
gies, however, an additional force appears. As it is well known, the interaction of several licensors creates a classical problem of Cournot complements, also known in this context as royalty stacking: by requiring a large royalty, innovators reduce the quantity that the final good producer sells, creating a negative externality on all the rest of the innovators. As a result, prices are higher than those that would emerge from the profit maximizing behavior of an upstream monopolist that holds all technologies. The model shows that the royalty stacking problem is more severe under per-unit royalties that under ad-valorem ones.

We introduce the incentives to innovate by assuming that in the first stage of the model both the upstream and downstream firms simultaneously must make an investment in the research and implementation of the technology, respectively. To the extent that success is only possible with the complementary investments of all firms, a typical problem of moral hazard in teams emerges (Holmstrom, 1982). Firms have individually insufficient incentives to invest. Since the choice of the royalty base affects the allocation of profits among the firms operating in different production stages it will also affect innovation and, consequently, social welfare.

In the context of an upstream and downstream monopoly, we have that ad-valorem royalties spur higher upstream investment, since they allocate more profits to the firm developing the technology. In the case of the downstream producer the comparison of the profits under ad-valorem and per-unit royalties depends on two opposing forces. On the one hand, ad-valorem royalties benefit the upstream producer, which might lead to lower downstream profits. On the other hand, total surplus under ad-valorem royalties is higher, since they mitigate the double-marginalization problem. When demand is isoelastic and the final price is independent of the royalty base used, the first force dominates, creating a trade-off in the provision of incentives to innovate. Thus, total welfare depends on the allocation of profits that maximizes the probability of success. As a result, 
if the cost of innovation of upstream producers is higher (lower) or the profits from the innovation outside of this vertical relationship are lower (higher), ad-valorem (per-unit) royalties would dominate from a social point of view, as they would globally engender more incentives to innovate. Furthermore, for the reasons stated before, since ad-valorem royalties also induce lower prices, they are more likely to become optimal.

When we consider multiple upstream developers with complementary innovations numerical results indicate that ad-valorem royalties typically work better. The reason is that by increasing upstream profits they generate a positive feedback on the incentive to innovate of all parties. In fact, for most parameter values even the incentives to invest of the downstream monopolist are higher under ad-valorem royalties, and so is social welfare. The positive effect due to lower prices is reinforced by the higher investment incentives.

More downstream competition makes the effects of ad-valorem and per-unit royalties more similar, since the double-marginalization (and the royalty stacking) problem becomes less severe. As a result, the impact on social welfare of the different rules is less significant and less clear-cut. Nevertheless, we observe that when the marginal cost of production is large total surplus is higher under ad-valorem royalties. It is only in the limit, when all downstream competitors sell an identical product that we find an equivalence between both kinds of contracts.

Overall, our results suggest that ad-valorem royalties tend to spur more innovation and lead to lower final prices, which explains their popularity. Very few papers in the literature have studied the trade-off between both types of royalties. Bousquet et al. (1998) compares ad-valorem and per-unit royalties in combination with fixed fees in the case of vertical relationships like the ones we consider here. They show that when there is uncertainty regarding the demand, typical of product innovations, ad-valorem royalties in combination with fixed fees are more effective for risk-sharing. In contrast, in the case 
of cost uncertainty, typical of process innovations, they show that the ranking between the two royalty schemes is far less clear.

Other papers have analyzed different trade-offs involving the two royalty bases and, in particular, their implications for raising rival's costs (Salop and Scheffman, 1983), when a vertically integrated firm licenses its technology to downstream competitors. San Martín and Saracho (2010) show that, under Cournot competition, ad-valorem royalties constitute a more effective commitment to soften downstream competition, raising the final price $5^{5}$

Another difference with previous works is that here we focus on how the royalty rate feeds back on the incentives for firms to innovate. For this reason, this paper is related to the literature on profit-sharing developed in Bhattacharyya and Lafontaine (1995). Whereas the focus of their work is in the design of ex-ante contracts that minimize the double moral hazard problem, here we assume that the terms of those contracts are agreed upon only after the innovation has taken place and only the type of contract is initially specified. We show that this difference typically makes the usage of fixed fees suboptimal since they exacerbate hold-up distortions.

Finally, this paper is also related to the literature that studies the optimal reward for complementary technologies in patent pools or standard-setting organizations. As in our paper, Gilbert and Katz (2011) study the incentives for innovators to carry out R\&D to uncover the complementary technologies that are embedded in complex products. Firms choose which technologies to pursue. They show that the optimal payoff from innovation must counterbalance two forces. On the one hand, firms cannot appropriate all the return from the innovation, leading to underinvestment. On the other hand, for each innovation firms engage in a patent race, leading to overinvestment. An important conclusion is that even in the case of perfectly complementary innovations an equal division of surplus

\footnotetext{
${ }^{5}$ Not very surprisingly, Colombo and Filippini (2012) show that the opposite is true when downstream firms compete in prices.
} 
among innovators is unlikely to be optimal, since it encourages firms to obtain either only one or all innovations. Instead, in this paper we focus on the interaction between upstream innovators and downstream producers. Since we assume that upstream innovators are identical and do not choose which technologies to pursue, equal division among them is optimal in our context. Furthermore, the lack of the patent race component always leads to underinvestment, resulting from the lack of appropriability of all the returns from the innovation.

The paper proceeds as follows. Section 2 and 3 discuss the benchmark model that includes an upstream and downstream monopolist and we allow for different allocations of bargaining power. Section 4 and 5 study the case of multiple upstream developers and downstream competitors, respectively. Section 6 concludes discussing policy implications. All proofs are relegated to an appendix.

\section{The Benchmark Model}

Consider the market for a new product. Its development requires the participation of two firms. A technology developer uncovers the basic technology that is required for the product. We denote this firm the upstream producer or $U$. Development also requires a downstream producer that adapts the technology and creates the final product that can be marketed. We denote this firm the downstream producer or $D$.

We treat the investment decisions of these firms symmetrically. Each firm exerts effort $e_{s}$, for $s=U, D$. Efforts are complementary in the development of the final product. In particular, we assume that the upstream technology is successful with probability $e_{U}$ and the downstream producer can adapt it successfully with probability $e_{D}$, so that the final product can be marketed with probability $e_{U} e_{D}$. Firms face an increasing and convex cost of effort $C\left(e_{s}\right)=\frac{1}{2} e_{s}^{2}$, for $s=U, D$.

Research effort may engender technologies that have alternative uses beyond the prod- 
uct considered. These uses lead to profits $\pi_{0}^{U}>0$ for the upstream producer if its research effort succeeds and $\pi_{0}^{D}>0$ if the final producer succeeds. These profits can originate, for example, from different applications of the technology developed upstream or from spillovers to other products that the downstream producer may already sell 6

The demand for the final product is $D(p)$. To simplify the analysis we will restrict most of the results to an isoelastic demand function $D(p)=p^{-\eta}$, with $\eta>1$. This specification also allows us to obtain closed-form solution for the main variables of the model.

The upstream developer charges a royalty rate to the final good producer. The downstream producer incurs in a marginal cost of production $c$ and after observing the royalty rate chooses the price in the final market, $p$. We compare two different bases on which the payment to the upstream developer is established, per-unit and ad-valorem royalties. The first base consists on a constant payment per-unit sold, $q=D(p)$, whereas the second base implies that the downstream firm transfers a share of its gross revenue, $p D(p)$, to the upstream producer.

To summarize, the timing of the model is as follows. In the first stage both firms choose simultaneously their level of effort. If effort leads to a successful product, the upstream innovator chooses the royalty rate in the second stage.7 In the last stage, the final price is set by the downstream producer. Notice that the structure of the model implies that contracts are incomplete. Effort is not ex-ante contractible. Furthermore, although firms may ex-ante agree on the type of contract to be used, the royalty is chosen only after the value of the innovation has been uncovered 8

\footnotetext{
${ }^{6}$ As we discuss later, differences in these outside profits have effects similar to differences in the cost of effort. In particular, $\pi_{0}^{D}>\pi_{0}^{U}$ will lead to implications equivalent to a lower marginal costs of effort for the downstream producer.

${ }^{7}$ In section 3 we show that the results are reinforced if the royalty rate is the result of a negotiation between the upstream and downstream firm.

${ }^{8}$ This kind of incompleteness is common in the literature on profit sharing and used in papers like Romano (1994) in the context of retail price maintenance contracts. In standard setting environments, Fair, Reasonable and Non-Discriminatory (FRAND) commitments are well-described by this timing.
} 
In the next subsections we characterize the subgame perfect equilibrium of the game. We start by comparing the equilibrium prices under both royalty bases. We then proceed to study how the incentives to innovate are affected by the royalty base.

\subsection{Equilibrium Royalties and Prices}

The downstream firm maximizes profits that depend on the royalty base used. Under per-unit royalties the firm chooses the monopoly price corresponding to a marginal cost $c+r$, where $r$ is the per-unit royalty that must be paid to the upstream developer. That is

$$
p^{*}(r)=\arg \max _{p}(p-c-r) D(p) .
$$

The upstream developer chooses $r$ maximizes licensing revenue, $r D\left(p^{*}(r)\right)$.

Under ad-valorem royalties, the upstream developer retains a proportion $s$ of the total revenue, $p D(p)$. As a result, the downstream producer chooses the price that results from

$$
p^{*}(s)=\arg \max _{p}[(1-s) p-c] D(p) .
$$

The upstream developer chooses $s$ to maximize licensing revenue, $s p^{*}(s) D\left(p^{*}(s)\right)$.

The first result show that under very weak regularity assumptions over demand advalorem royalties always lead to lower (or equal) prices than per-unit ones. In other words the double-marginalization problem typical of vertical relations like the one assumed in this model is less severe under ad-valorem royalties.

Proposition 1. Assume that $D(p)$ is a twice-continuously differentiable demand function with a price elasticity $\eta(p)$ increasing in $p$. Then, under successive monopolies,

1. if an ad-valorem royalty and a per-unit one lead to the same final price, the advalorem royalty results in higher upstream profits.

2. The ad-valorem royalty that maximizes upstream profits leads to a lower final price than the per-unit royalty that maximizes upstream profits. 
First notice that the result holds for a large family of demand functions, the isoelastic one being a limiting case. It includes most typical demand functions like the linear demand and, more generally, log-concave demand functions, a class of demand specifications which guarantee that the first-order condition is sufficient.

The first part of the proposition shows that for a given final price an ad-valorem royalty allows the upstream innovator to extract a larger share of surplus from the relationship with the downstream producer. Remarkably, this result, although it has never been stated in the context of licensing contracts is a classical result in the public finance literature. Much of the early literature on indirect taxation discussed whether these taxes should be based on the units sold (per-unit) or the value of sales (ad-valorem). In the context of a market monopolist Suits and Musgrave (1953) show that contingent on raising the same revenue, ad-valorem royalties turn out to be less distorting and, therefore, are superior from a social stand-point. An immediate consequence of this result is that upstream profits will always be higher under ad-valorem royalties.

The second part of the proposition characterizes the optimal ad-valorem royalty. The proof shows that compared to the situation in which both types of royalty yield the same final price, it is optimal for the upstream innovator to lower the ad-valorem royalty 9 Of course, given that the equilibrium price is above the monopoly price, ad-valorem royalties not only increase profits for the upstream producer but at the same time increase consumer welfare.

The intuition for the previous result is that ad-valorem royalties are closer to fixed fees, which are optimal in this context since they are free from the double-marginalization effect. It is easy to see that if marginal cost were equal to 0 , ad-valorem royalties would

\footnotetext{
${ }^{9}$ Gaudin and White (2014) derive a counterpart of this result in the context of taxation and show that the result is robust to other assumptions on downstream competition.
} 
indeed be equivalent to fixed fees, since the downstream producer maximizes

$$
\max _{p}(1-s) p D(p)
$$

leading to an optimal price $p^{*}$ equal to the monopoly price and, thus, independent of the royalty paid. As a result, upstream profits do not entail a social cost when $c=0$. As the marginal cost becomes more relevant, however, the difference between the two kinds of royalties becomes less significant. The next example, using a linear demand function, illustrates this intuition.

Example 1 (Linear Demand). Consider a linear demand function $D(p)=1-p$. Standard algebra implies that under per-unit royalties the equilibrium royalty rate becomes $r^{*}=\frac{1-c}{2}$, leading to an equilibrium price $p_{p u}^{*}=\frac{3+c}{4}$, where pu stands for per-unit royalties. Profits can be computed as

$$
\begin{aligned}
\Pi_{U, p u}^{*} & =\frac{(1-c)^{2}}{8}, \\
\Pi_{D, p u}^{*} & =\frac{(1-c)^{2}}{16} .
\end{aligned}
$$

Under ad-valorem royalties the objective function of the upstream developer becomes a fourth-degree polynomial which yields a substantially more complicated expression for the optimal royalty, which can be written as

$$
s^{*}=\left(\frac{c^{2} \sqrt{c^{2}+27}}{3^{\frac{3}{2}}}-c^{2}\right)^{\frac{1}{3}}-\frac{c^{2}}{3\left(\frac{c^{2} \sqrt{c^{2}+27}}{3^{\frac{3}{2}}}-c^{2}\right)^{\frac{1}{3}}}+1 .
$$

The equilibrium price corresponds to $p_{a v}^{*}=\frac{1+c-s^{*}}{2\left(1-s^{*}\right)}$, where av stands for ad-valorem royalties, and profits can be computed as

$$
\begin{aligned}
\Pi_{U, a v}^{*} & =s^{*} \frac{1-c-s^{*}}{2\left(1-s^{*}\right)}, \\
\Pi_{D, a v}^{*} & =\frac{\left(1-c-s^{*}\right)^{2}}{4\left(1-s^{*}\right)} .
\end{aligned}
$$


The top three graphs in Figure 1 illustrate numerically the equilibrium prices and profits that arise from the previous expressions. The royalty that the upstream innovator sets must trade-off a large royalty and a small quantity resulting from double-marginalization. Following the intuition discussed above this effect does not exist under ad-valorem royalties when the marginal cost is 0 , since in that case they effectively behave like a fixed fee. This fact explains why the price, confirming the result stated in Proposition 1, is lower under this royalty base, and the difference is higher for a low marginal cost. As the marginal cost increases, the double-marginalization effect becomes more relevant under ad-valorem royalties narrowing the gap between the resulting price and the one that emerges under per-unit royalties.

The figure also illustrates after-investment profits under both kinds of royalties. The result is, as expected, that upstream profits are higher under ad-valorem royalties where the opposite is true for the downstream producer. However, an important difference between the two kinds of royalties is that under ad-valorem royalties the downstream producer makes profits that are not monotonic in the cost. Using the intuition discussed before about the price, when the marginal cost is low, the upstream producer can charge a high royalty without distorting much the price. As marginal cost increases, however, this royalty must be decreased in order to keep the price low which, for some values, compensates the producer for the higher marginal cost incurred.

Example 2 (Isoelastic Demand). Consider an isoelastic demand function $D(p)=p^{-\eta}$ with $\eta>1$. It is easy to show that the optimal per-unit royalty corresponds to $r^{*}=\frac{c}{\eta-1}$. The final price can be computed as $p_{p u}^{*}=c\left(\frac{\eta}{\eta-1}\right)^{2}$, where pu stands for per-unit royalties. Profits become

$$
\begin{aligned}
\Pi_{U, p u}^{*} & =\frac{(\eta-1)^{2 \eta-1}}{\eta^{2 \eta}} c^{1-\eta} \\
\Pi_{D, p u}^{*} & =\frac{(\eta-1)^{2(\eta-1)}}{\eta^{2 \eta-1}} c^{1-\eta}
\end{aligned}
$$




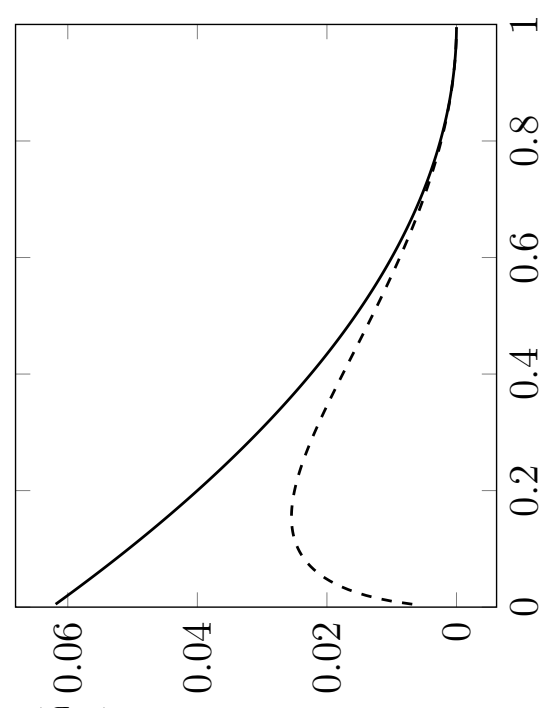

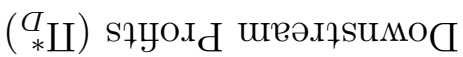

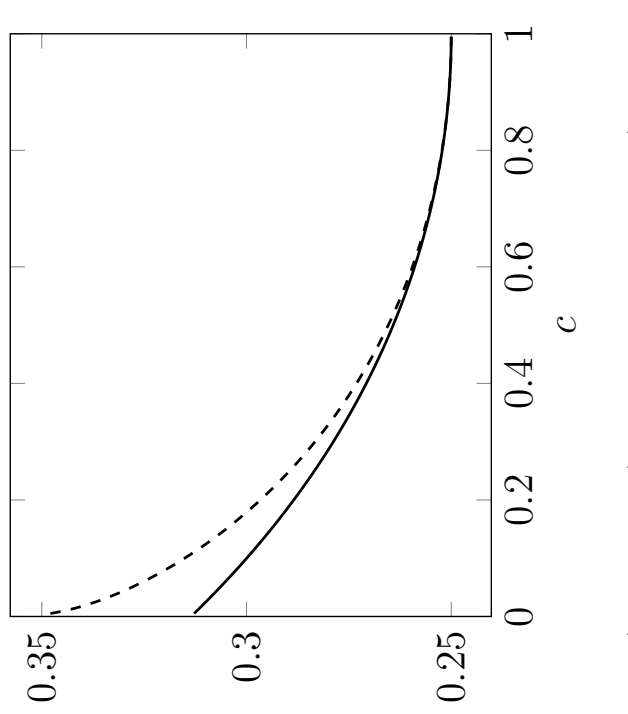

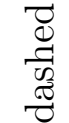

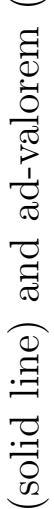

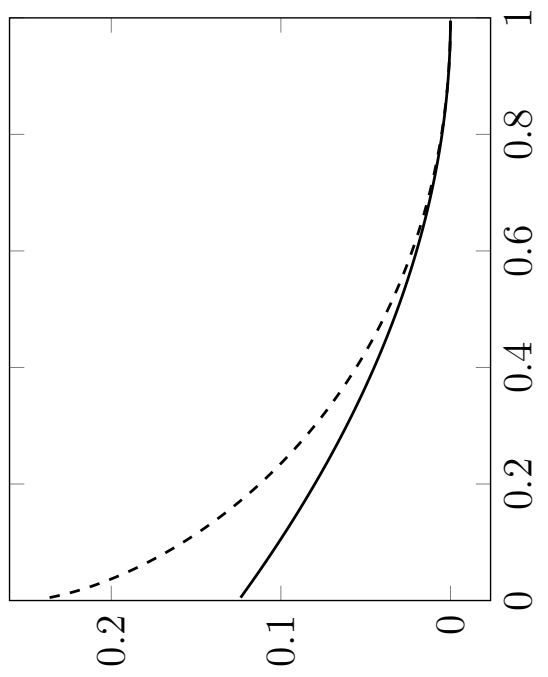

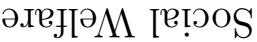

节

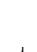

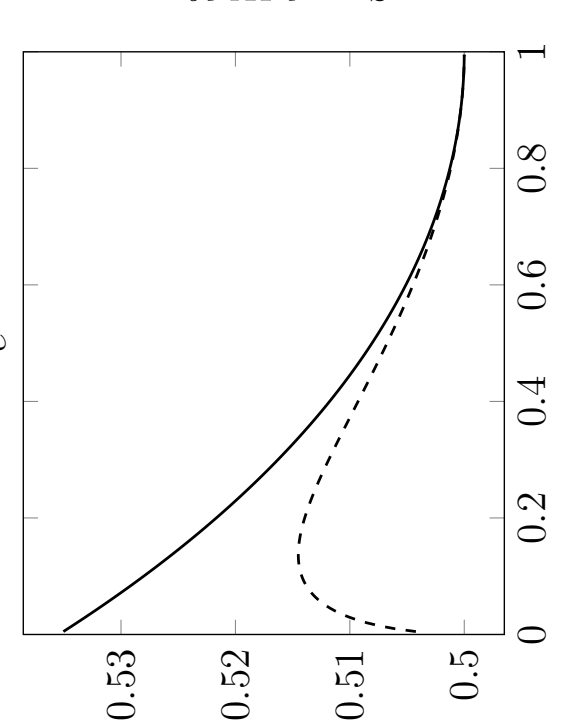

要

䒯 $\|$

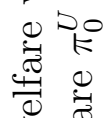

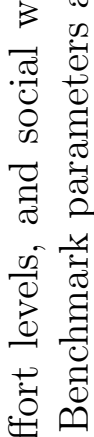

$\left({ }_{*} \amalg\right)$ słyo. ${ }_{\mathrm{d}}$ шеәлұsd

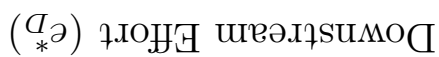

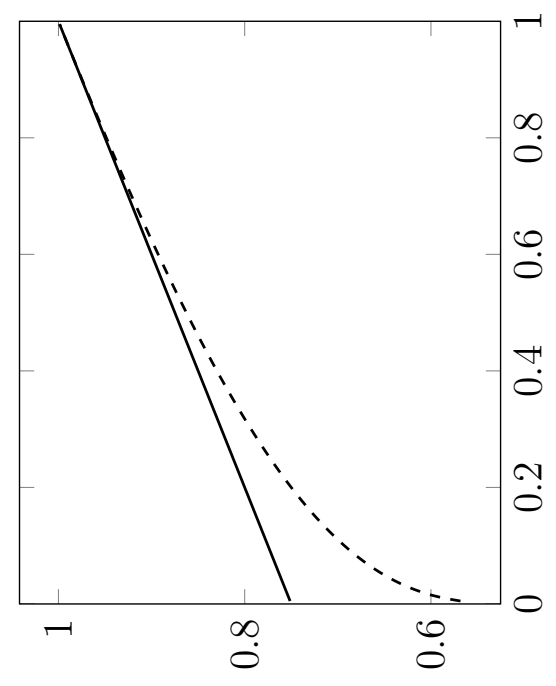

$\left.{ }_{*} d\right)$ әəเ̣.

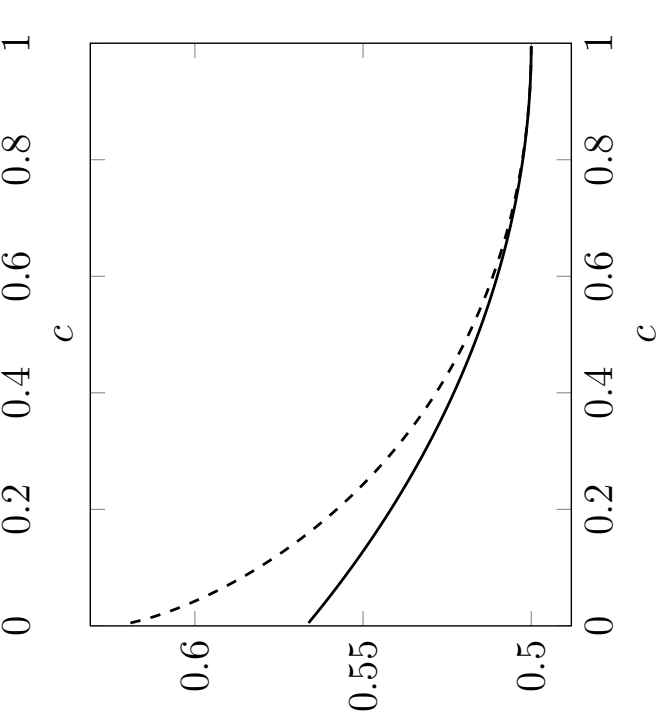

$\left({ }_{*}{ }^{\circ}\right)$ ᄀлоШя̈ шеәлұsd
象

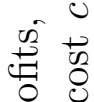

ล.

范 $\cdot \frac{7}{0}$

离茪

西

के

.$\Xi$

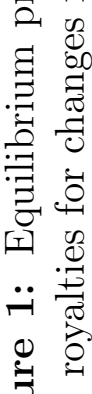

焉 
implying that per-unit royalties allocate a higher share of the total surplus to the downstream producer, $\Pi_{D, p u}^{*}>\Pi_{U, p u}^{*}$.

Under ad-valorem royalties the equilibrium royalty rate and price can be shown to be $s^{*}=\frac{1}{\eta}$ and $p_{a v}^{*}=c\left(\frac{\eta}{\eta-1}\right)^{2}$, respectively.

Notice that the price is identical under per-unit and ad-valorem royalties, $p_{p u}^{*}=p_{a v}^{*}$. However, profits are different. In particular,

$$
\begin{aligned}
\Pi_{U, a v}^{*} & =\frac{(\eta-1)^{2(\eta-1)}}{\eta^{2 \eta-1}} c^{1-\eta}, \\
\Pi_{D, a v}^{*} & =\frac{(\eta-1)^{2 \eta-1}}{\eta^{2 \eta}} c^{1-\eta} .
\end{aligned}
$$

Notice that $\Pi_{U, a v}^{*}=\Pi_{D, p u}^{*}$ (and obviously $\Pi_{D, a v}^{*}=\Pi_{U, p u}^{*}$ ). In contrast to what happens under per-unit royalties, ad-valorem royalties lead to higher profits for the upstream producer.

The previous example shows that the isoelastic demand is a corner case of the result in Proposition 1, one in which the prices are identical regardless of the royalty base. This result will become handy in the rest of the paper in which we will maintain the assumption that demand is isoelastic.

Assumption 1. Demand is isoelastic, $D(p)=p^{-\eta}$, with $\eta>1$.

This assumption on the one hand provides analytical tractability, allowing us to obtain close form solution for most variables of the model. Furthermore, by leading to the same price under both royalty bases it will allow us to disentangle the effects of Proposition 1 from those that will emerge once innovation incentives are considered or other market structures, including upstream complementary innovations or downstream competition are discussed later in the paper. It also implies that the positive effects of ad-valorem royalties on social welfare will be underestimated once we consider other demand structures. 


\subsection{First Stage Effort}

In the first stage firms simultaneously choose their research effort. Denote the generic expression for profits of the upstream and downstream firm resulting from the royalty and posterior pricing stages as $\Pi_{U}$ and $\Pi_{D}$, respectively.

The downstream producer chooses effort $e_{D}$ to maximize profits from the new product as well as profits from the alternative use of the innovation, net of the cost of this effort. That is, the optimal effort arises from

$$
\max _{e_{D}} e_{U} e_{D} \Pi_{D}+e_{D} \pi_{0}^{D}-\frac{1}{2} e_{D}^{2}
$$

In a symmetric way, the level of effort $e_{U}$ that maximizes profits for the upstream producer can be obtained from

$$
\max _{e_{U}} e_{U} e_{D} \Pi_{U}+e_{U} \pi_{0}^{U}-\frac{1}{2} e_{U}^{2}
$$

The first-order conditions for both firms lead to the following reaction functions:

$$
\begin{aligned}
& e_{U}^{R}\left(e_{D}\right)=e_{D} \Pi_{U}+\pi_{0}^{U}, \\
& e_{D}^{R}\left(e_{U}\right)=e_{U} \Pi_{D}+\pi_{0}^{D},
\end{aligned}
$$

and combining both reaction functions we obtain the corresponding unique equilibrium effort decisions

$$
\begin{aligned}
e_{U}^{*} & =\frac{\pi_{0}^{D} \Pi_{U}+\pi_{0}^{U}}{1-\Pi_{U} \Pi_{D}}, \\
e_{D}^{*} & =\frac{\pi_{0}^{U} \Pi_{D}+\pi_{0}^{D}}{1-\Pi_{U} \Pi_{D}} .
\end{aligned}
$$

Due to the complementarity of efforts, the higher the incentive a firm has to exert effort the more productive will be the effort of the other firm. That result suggests that there might be instances in which one firm obtains a lower proportion of the surplus and yet effort increases due to the increase in the total surplus accrued by both firms. 
The fact that under an isoelastic demand function the price is independent of whether ad-valorem or per-unit royalties are used implies that, contingent on success, consumer surplus is identical regardless of the kind of royalty base that the upstream developer chooses. Furthermore, since total profits are the same in both cases, total welfare from the production of the good, contingent on the innovation being successful, is independent of the base used to compute the royalty.

Nevertheless, the division of the surplus might have significant implications for the level of effort being exerted in the first place and, therefore, in the ex-ante expected welfare. Interestingly, the next proposition states that the ranking between both kinds of royalty structures depends only on the outside profits of both firms.

Proposition 2. If the upstream and downstream producer are monopolists and under an isoelastic demand function, ex-ante social welfare is higher with ad-valorem royalties if and only if $\pi_{0}^{D} \geq \pi_{0}^{U}$.

In order to understand the previous result it is useful to start with the case in which both firms obtain the same profits from the alternative uses of the innovation. Remember that the downstream producer benefits more from the production of the good under per-unit royalties and the upstream producer benefits more under ad-valorem royalties. Thus, it is immediate from equations (3) and (4) that under per-unit royalties a higher proportion of the investment is carried out by the downstream producer, whereas under ad-valorem royalties a higher proportion is carried out by the upstream developer. However, due to the symmetry in the profits that firms get in each of the cases, the total probability of success is preserved in both cases leading to identical social welfare in both situations.

Increases in $\pi_{0}^{D}$ (alternatively in $\pi_{0}^{U}$ ) lead to an increase in the investment of the downstream (alternatively, the upstream) producer, as it can be appreciated from (2) (and 
(1)). In equilibrium, both firms increase their investment due to the complementarity of efforts. As we pointed out before, the two bases over which royalties can be computed represent a trade-off, since increasing the profits and incentives to one party lowers the equilibrium incentives of the other. The previous argument suggests that when $\pi_{0}^{D}$ is high compared to $\pi_{0}^{U}$, the downstream producer already has high incentives to invest. Choosing a per-unit royalty will have little effect on downstream incentives due to the convex cost of effort, while the lower profits it implies for the developer will discourage upstream investment.

Using the same arguments we can conclude that the previous result would hold if, for example, we use consumer or producer surplus as a measure of welfare rather than total surplus. The reason is that since the price is the same in both scenarios, contingent on success, consumer surplus and producer surplus will stay unchanged. Thus, these measures of welfare are maximized when the probability of success is highest - given that the first level of effort will never be attained -, which occurs under ad-valorem royalties for $\pi_{0}^{D} \geq \pi_{0}^{U}$.

Remark 1. Under the conditions of Proposition 2, consumer surplus and producer surplus are higher under ad-valorem royalties if and only if $\pi_{0}^{D} \geq \pi_{0}^{U}$.

Similar results could be obtained if we assumed that outside profits were the same for both firms but the marginal cost of effort was different. In particular, if the cost of effort were lower for the downstream producer so that it would naturally tend to make a higher investment, ad-valorem royalties would be optimal, as they would spur upstream effort. In particular, if the marginal costs of effort were $C_{U}^{\prime}\left(e_{U}\right)=a_{U}+e_{U}$ and $C_{D}^{\prime}\left(e_{D}\right)=a_{D}+e_{D}$, ad-valorem royalties would lead to higher welfare if and only if $a_{D} \leq a_{U}$.

If Assumption 1 is relaxed, ad-valorem royalties are more likely to be optimal. Consider the linear demand discussed in Example1. Figure11 includes the simulation of effort 
decisions and ex-ante social welfare assuming that outside profits are identical. Although per-unit royalties spur the investment of the downstream producer and ad-valorem royalties spur the investment of the upstream developer the two effects are not of the same magnitude. The probability of success is higher under ad-valorem royalties since the double-marginalization effect is smaller and, thus, total profits are higher in this case.

The combination of the higher incentives to innovate together with a lower price makes social welfare higher under ad-valorem royalties. Of course, as in the isoelastic case, the results could be overturned by choosing $\pi_{0}^{U}$ sufficiently higher than $\pi_{0}^{D}$. Numerical simulations suggest, however, that this difference might need to be substantial for such a change to occur.

\section{Bargained Royalty Rate}

Although the assumption that the upstream producer makes a take-it-or-leave-it offer simplified our analysis it is not particularly realistic in many situations. For this reason we now generalize the model and assume that the royalty rate is the result of a bargaining process between the upstream and the downstream producer. The final price, however, is still independently chosen by the downstream firm.

In particular, we assume that the equilibrium royalty emerges as the result of Nash bargaining in which the bargaining power of the upstream and downstream firms are $\gamma$ and $1-\gamma$, respectively, for $\gamma \in[0,1]$. Since the contribution of the upstream and downstream parties is essential for the product to be marketable, the outside option in the negotiation of each of the parties is set to 0 .

Contingent on successful development and given a royalty $r$, previous calculations imply that the final price is $p^{*}(r)=(c+r) \frac{\eta}{\eta-1}$. Profits correspond to $\Pi_{U}(r)=r\left(p^{*}(r)\right)^{-\eta}$ and $\Pi_{D}(r)=\left(p^{*}(r)-(c+r)\right) p^{*}(r)^{-\eta}$. Hence, the equilibrium royalty results from

$$
r^{*}=\arg \max _{r} \Pi_{U}(r)^{\gamma} \Pi_{D}(r)^{1-\gamma},
$$




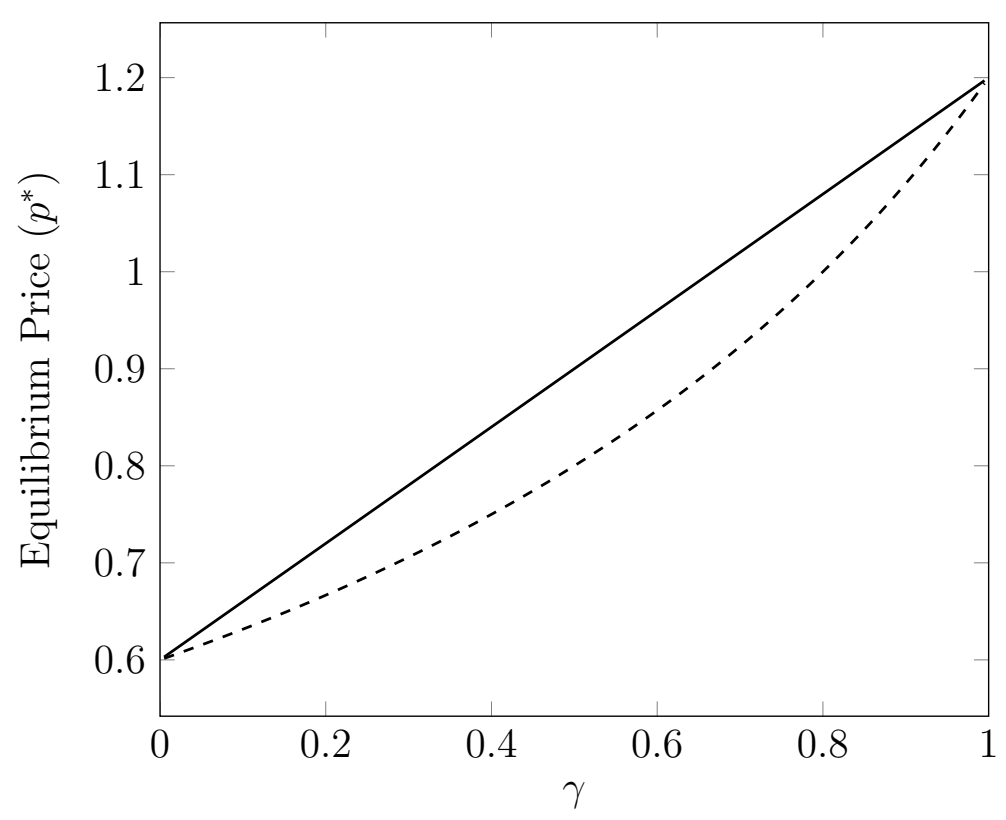

Figure 2: Final price under per-unit (solid line) and ad-valorem (dashed line) royalties given bargaining power $\gamma$. The parameter values used are $c=0.3, \eta=2$.

or $r^{*}=\frac{\gamma c}{\eta-1}$. The equilibrium price becomes $p_{p u}^{*}=c \frac{\eta(\eta+\gamma-1)}{(\eta-1)^{2}}$. This price, of course, is increasing in $\gamma$, as the problem of double-marginalization becomes more important the higher the bargaining power allocated upstream.

Under ad-valorem royalties, given a royalty $s$, the final price is $p^{*}(s)=\frac{c \eta}{(1-s)(\eta-1)}$. Profits can be written as $\Pi_{U}(s)=s\left(p^{*}(s)\right)^{1-\eta}$ and $\Pi_{D}(r)=\left((1-s) p^{*}(s)-c\right) p^{*}(s)^{-\eta}$. The equilibrium royalty results from

$$
s^{*}=\arg \max _{s} \Pi_{U}(s)^{\gamma} \Pi_{D}(s)^{1-\gamma},
$$

or $s^{*}=\frac{\gamma}{\eta}$. The final price is then $p_{a v}^{*}(s)=c \frac{\eta^{2}}{(\eta-1)(\eta-\gamma)}$. As before, this price is increasing in $\gamma$.

The comparison of the two prices leads to the following proposition.

Proposition 3. In successive monopolies, for any bargaining power $\gamma \in(0,1)$, per unit royalties lead to strictly higher prices than ad-valorem royalties. For $\gamma=0$ and $\gamma=1$ the price is independent of the royalty base.

As expected, when $\gamma=0$ both royalty bases lead to the same final price since the case 
in which all bargaining power is allocated downstream implies $r^{*}=s^{*}=0$. The final price is, therefore, the monopoly one. Similarly, when $\gamma=1$ the result in Proposition 2 applies. Interestingly, in the intermediate situation the price is systematically higher with per-unit royalties exacerbating the double-marginalization problem. This difference is illustrated in Figure 2. The reason is that both parties internalize a part of the doublemarginalization problem that the vertical relationship generates, and ad-valorem royalties are more effective in aligning the incentives, as they take into account the effect on the price.

Regarding the incentives to innovate, we know that for $\gamma=0$ ad-valorem and per-unit royalties coincide, leading to identical profits and identical incentives to innovate. When the bargaining power of the upstream producer increases, however, two forces emerge. On the one hand, we have that the lower price and higher total profits that ad-valorem royalties entail could feed back into higher incentives to innovate. On the other hand, advalorem royalties would tend to allocate more profits to the upstream producer distorting the incentives of the downstream producer to exert effort.

The first effect is likely to dominate when $\gamma$ is low, since as we can see in Figure 2 price differences increase as more bargaining power is allocated to the upstream producer. When $\gamma$ is high, however, price differences shrink as $\gamma$ increases and the second effect will dominate. This is exactly what happens when $\gamma=1$ and, as we saw in Proposition 2, a lower outside option for the downstream producer (compared to the upstream one) could make ad-valorem royalties worse for innovation than per-unit ones.

The previous discussion is also helpful in order to understand the consequences of enlarging the family of contracts we consider. Suppose, in particular, that in our benchmark model we allow for fixed fees (alone or in combination with royalties). In that case, it is immediate that the contract that firms ex-post will agree on includes a 0 royalty together with a fixed fee that splits total surplus according to each firm's bargaining power. As a 
result, the first effect will be maximized, since no double marginalization will take place and total surplus will be maximized.

The second effect, however, will also become more significant in this case. In particular, suppose that $\gamma=1$ so that the upstream producer has all the bargaining power. It is still the case that total surplus is higher under fixed fees than if the upstream producer could only use royalties (either per-unit or ad-valorem). Nevertheless, in that case, the equilibrium fixed fee will extract of all profits from the downstream producer who, in anticipation, will choose to exert minimum effort, $e_{D}^{*}=\pi_{0}^{D}$. In instances in which the success hinges significantly on the effort of the downstream firm and/or $\pi_{0}^{D}$ is low, fixed fees will lead to lower profits and lower incentives to innovate 10

\section{Multiple Upstream Developers}

In this section we extend the previous framework to consider the possibility that there might be several upstream firms that contribute different pieces of the technologies necessary for the downstream product to be successful. In particular, we assume that there are $N_{U}>1$ components researched by $N_{U}$ different developers. Component $i$ is researched by upstream firm $i$, for $i=1, \ldots, N_{U}$. We assume that these components are symmetric so that the cost for developer $i$ of exerting effort $e_{U}^{i}$ is $C\left(e_{U}^{i}\right)=\frac{1}{2}\left(e_{U}^{i}\right)^{2}$. Similarly, the probability of success is symmetric and equal to

$$
E=\left(\sum_{i=1}^{N_{U}}\left(e_{U}^{i}\right)^{\alpha}\right)^{\frac{1}{\alpha}} e_{D}
$$

where $\alpha \in[0,1]$ measures the degree of independence of the different innovations. When $\alpha$ is high the effect of effort of firm $i$ on the productivity of the effort of firm $j$ is small. As $\alpha$ decreases innovations become more complementary. The existence of a Standard

\footnotetext{
${ }^{10}$ Even in less extreme cases, the bad of risk-sharing properties of fixed fees makes them unattractive as a way to split surplus in licensing agreements. They are often observed in combination with royalties, but as a way for licensees to compensate patent holders for previous infringement damages.
} 
Setting Organization (SSO) that aims to coordinate the firms that provide technologies for a product would be consistent with a low value of $\alpha{ }^{11}$ As before, we assume that the alternative uses of each innovation carried out by an upstream producer lead to profits $\pi_{0}^{U}>0$. We assume, as in section 2 that upstream producers have all bargaining power.

In the first stage firms simultaneously choose their research effort. The unique downstream producer chooses $e_{D}$ to maximize

$$
\max _{e_{D}}\left(\sum_{i=1}^{N_{U}}\left(e_{U}^{i}\right)^{\alpha}\right)^{\frac{1}{\alpha}} e_{D} \Pi_{D}+e_{D} \pi_{0}^{D}-\frac{1}{2} e_{D}^{2} .
$$

Upstream developer $i$ chooses $e_{U}^{i}$ to maximize,

$$
\max _{e_{U}^{i}}\left(\sum_{i=1}^{N_{U}}\left(e_{U}^{i}\right)^{\alpha}\right)^{\frac{1}{\alpha}} e_{D} \Pi_{U}+e_{U}^{i} \pi_{0}^{U}-\frac{1}{2}\left(e_{U}^{i}\right)^{2} .
$$

In a symmetric equilibrium we have a generalization of equations (3) and (4) to $N_{U}>1$, implying that

$$
\begin{aligned}
& e_{D}^{*}=\frac{N_{U}^{1 / \alpha} \Pi_{D} \pi_{0}^{U}+\pi_{0}^{D}}{1-N_{U}^{\frac{2-\alpha}{\alpha}} \Pi_{U} \Pi_{D}}, \\
& e_{U}^{*}=\frac{N_{U}^{\frac{1-\alpha}{\alpha}} \Pi_{U} \pi_{0}^{D}+\pi_{0}^{U}}{1-N_{U}^{\frac{2-\alpha}{\alpha}} \Pi_{U} \Pi_{D}} .
\end{aligned}
$$

The same kind of complementarity discussed in the case of one upstream developer operates here between different developers. Keeping profits constant, increases in $N_{U}$ raise the probability of success of the innovation and thus the incentives of all parties to invest. Of course, profits in the final stages of the game will change as $N_{U}$ increases, affecting this result. We now analyze the direction of these changes and, in particular, how the profits of the upstream developers and the downstream producers are shaped under the different bases for the royalty rate as $N_{U}$ increases.

\footnotetext{
${ }^{11}$ Nevertheless, we assume that all components are required for the final product, as in the case of Standard Essential Patents (SEPs). In Appendix B we show that results still hold when we relax this assumption and allow for innovations to be substitutes.
} 


\subsection{Per-Unit Royalties}

Under per-unit royalties, the total royalty rate that the downstream producer faces is $R \equiv \sum_{i}^{N_{U}} r_{i}$. Thus, the optimal downstream price is identical to the one in the case in which $N_{U}=1$ obtained before but applied to the total rate, $p^{*}(R)=\frac{\eta}{\eta-1}(c+R)$.

Anticipating that price, all upstream developers simultaneously choose their royalty rate $r_{i}$, for $i=1, \ldots, N_{U}$ to maximize profits. For developer $i$ this maximization implies

$$
\max _{r_{i}} r_{i}\left(p^{*}(R)\right)^{-\eta}
$$

Differentiating with respect to $r_{i}$ and focusing on a symmetric equilibrium, in which $r_{i}=r^{*}$ for all $i$, we have that

$$
r^{*}=\frac{c}{\eta-N_{U}} \text { and } p_{p u}^{*}=\frac{\eta^{2}}{(\eta-1)\left(\eta-N_{U}\right)} c
$$

which are defined only if $\eta>N_{U}$. We see that the higher the number of upstream producers the higher the price in the final market and, thus, the larger the final market distortions. This result is a standard application of the idea of Cournot complements. Upstream developers only take into account the effect of their royalty on their own profits but not the fact that it reduces the quantity that is also the base of the revenues of all other upstream developers.

Profits can be computed as

$$
\begin{aligned}
\Pi_{U, p u}^{*} & =\frac{\left(\eta-N_{U}\right)^{\eta-1}(\eta-1)^{\eta}}{\eta^{2 \eta}} c^{1-\eta} \\
\Pi_{D, p u}^{*} & =\frac{\left(\eta-N_{U}\right)^{\eta-1}(\eta-1)^{\eta-1}}{\eta^{2 \eta-1}} c^{1-\eta},
\end{aligned}
$$

which are decreasing in $N_{U}$ due to the previous effect.

\subsection{Ad-Valorem Royalties}

Under ad-valorem royalties the total royalty rate is again $S \equiv \sum_{i}^{N_{U}} s_{i}$. Using the expression for the royalty in the case of $N_{U}=1$ applied to the total royalty rate we have that 
$p^{M}(S)=\frac{\eta}{(1-S)(\eta-1)} c$.

Upstream developer $i$ chooses $s_{i}$ in the first stage to maximize

$$
\max _{s_{i}} s_{i}\left(p^{*}(S)\right)^{1-\eta}
$$

Differentiating with respect to $s_{i}$ and focusing on a symmetric equilibrium, in which $s_{i}=s^{*}$ for all $i$, we have that

$$
s^{*}=\frac{1}{\eta+N_{U}-1} \text { and } p_{a v}^{*}=\frac{\eta\left(\eta+N_{U}-1\right)}{(\eta-1)^{2}} c
$$

where as before the price is increasing in $N_{U}$. Profits can be computed as

$$
\begin{aligned}
\Pi_{U, a v}^{*} & =\frac{(\eta-1)^{2 \eta-2}}{\eta^{\eta-1}\left(\eta+N_{U}-1\right)^{\eta}} c^{1-\eta} \\
\Pi_{D, a v}^{*} & =\frac{(\eta-1)^{2 \eta-1}}{\eta^{\eta}\left(\eta+N_{U}-1\right)^{\eta}} c^{1-\eta}
\end{aligned}
$$

\subsection{Comparison}

We start by analyzing the pricing stage, once investment has been carried out and all components of the innovation has been successfully developed, both upstream and downstream.

Proposition 4. Suppose that innovation efforts have been successful. Under ad-valorem royalties the final price is lower, $p_{a v}^{*} \leq p_{p u}^{*}$. Furthermore, upstream producers' profits are higher under ad-valorem royalties whereas the downstream producer's profits are higher under per-unit royalties.

Some of the results obtained in the case of one upstream developer are preserved in this case. It still true that ad-valorem royalties tend to favor upstream developers, compared to the downstream producer, whereas the opposite is true for per-unit royalties. An important difference, however, is that ad-valorem royalties lead to lower downstream prices. Thus, ex-post consumer surplus is lower under per-unit royalties. 


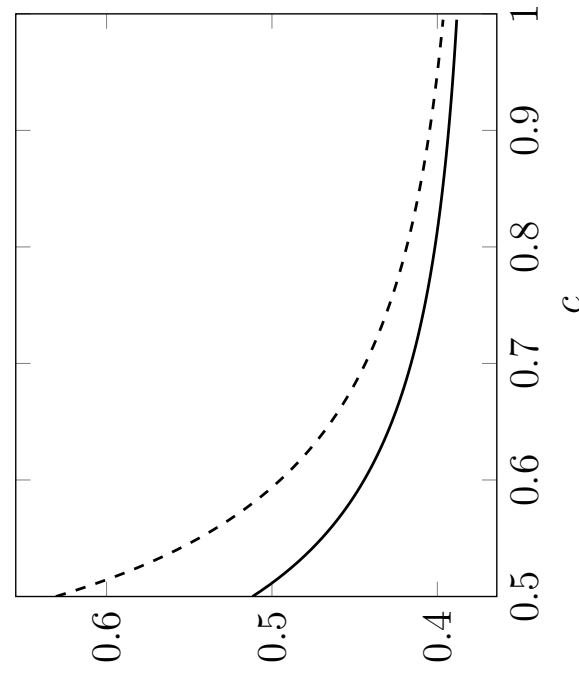

әІРҒ[РМ IR7OL

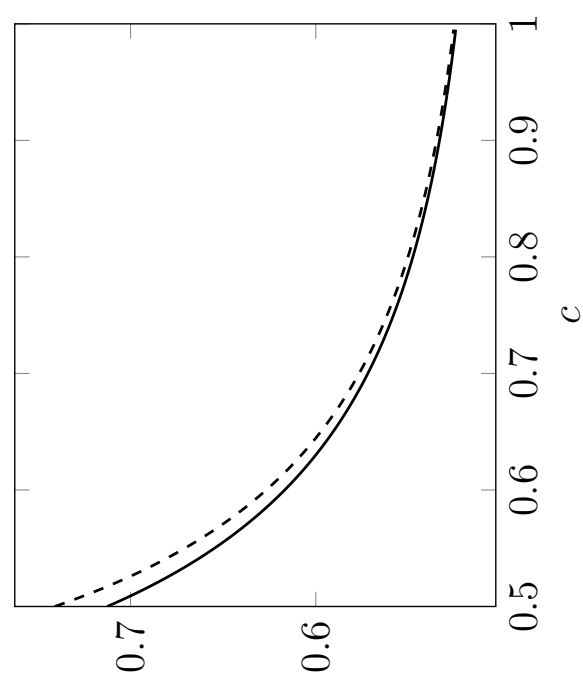

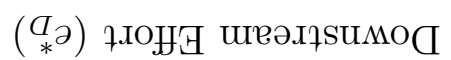

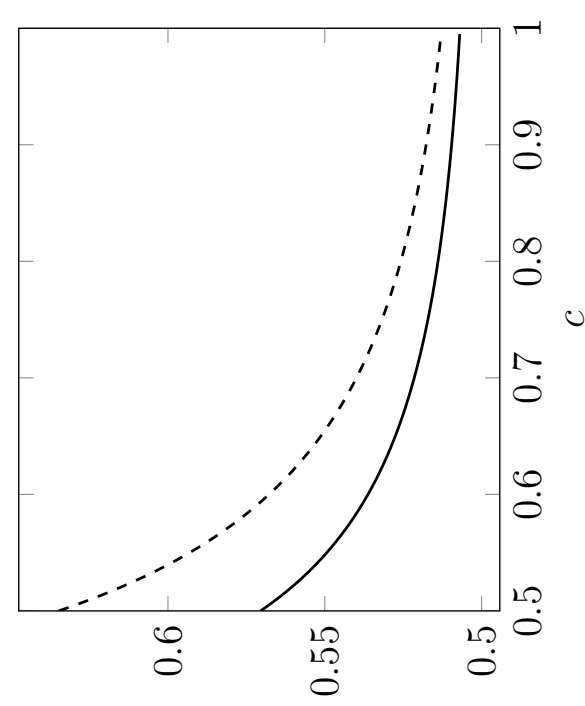

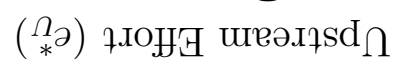
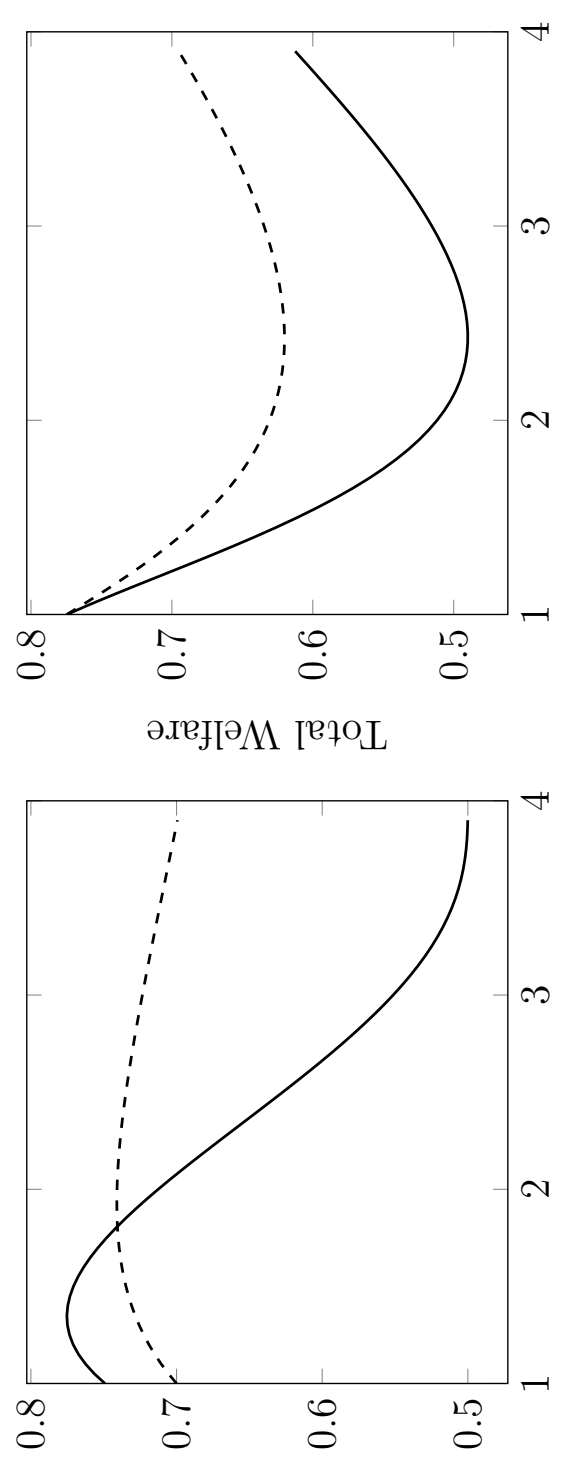

$\left(\begin{array}{l}a_{*} \\ *\end{array}\right)$ ұлоША шеәлұsumo

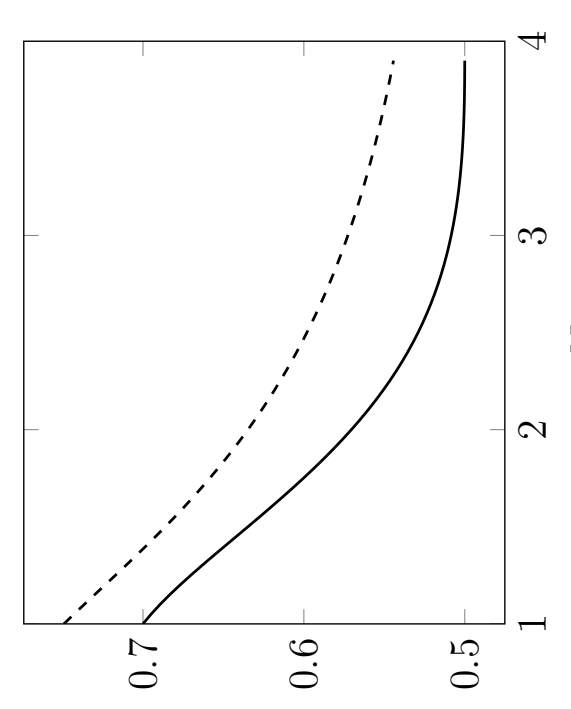

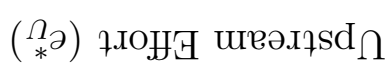

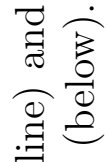

$\underset{7}{*}$

@ की

$z$

:

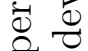

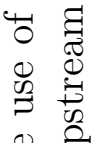

త $\overbrace{\Xi}^{2}$

फे

莺

䒕 政

Ð

¿

元䨌

¿ृ

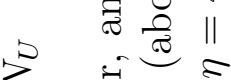

¿্ं 0

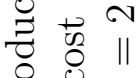

光范之

串

0

पै द्वा

造告

. $.0^{\circ}$

If 11

की

岂

잉요

e 0

द्व

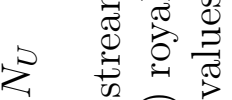

艺:

它击

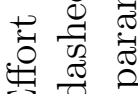

田

ले छृ

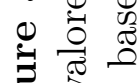

焉 

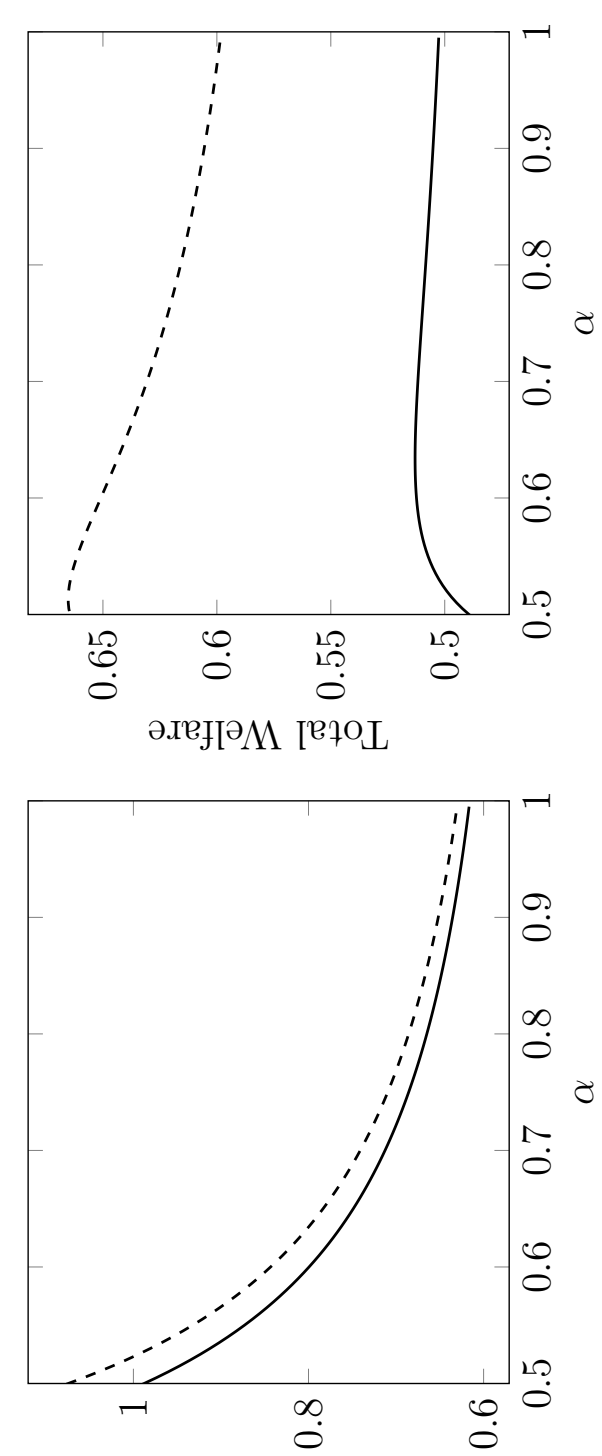

$\left({ }_{*}^{a_{2}}\right.$ ) ұлоШЯ шеәлұsuмо

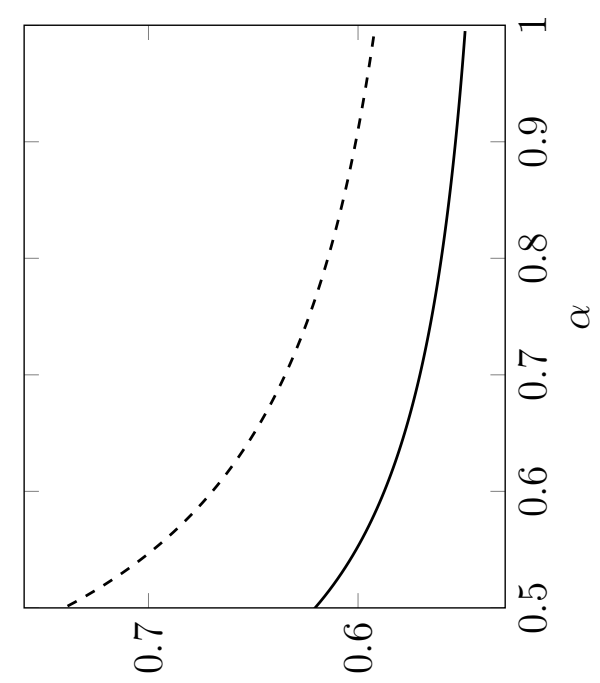

$\left({ }_{*}\right.$ ว $)$ ᄀ.ОШЯ̈ шеәлұsd

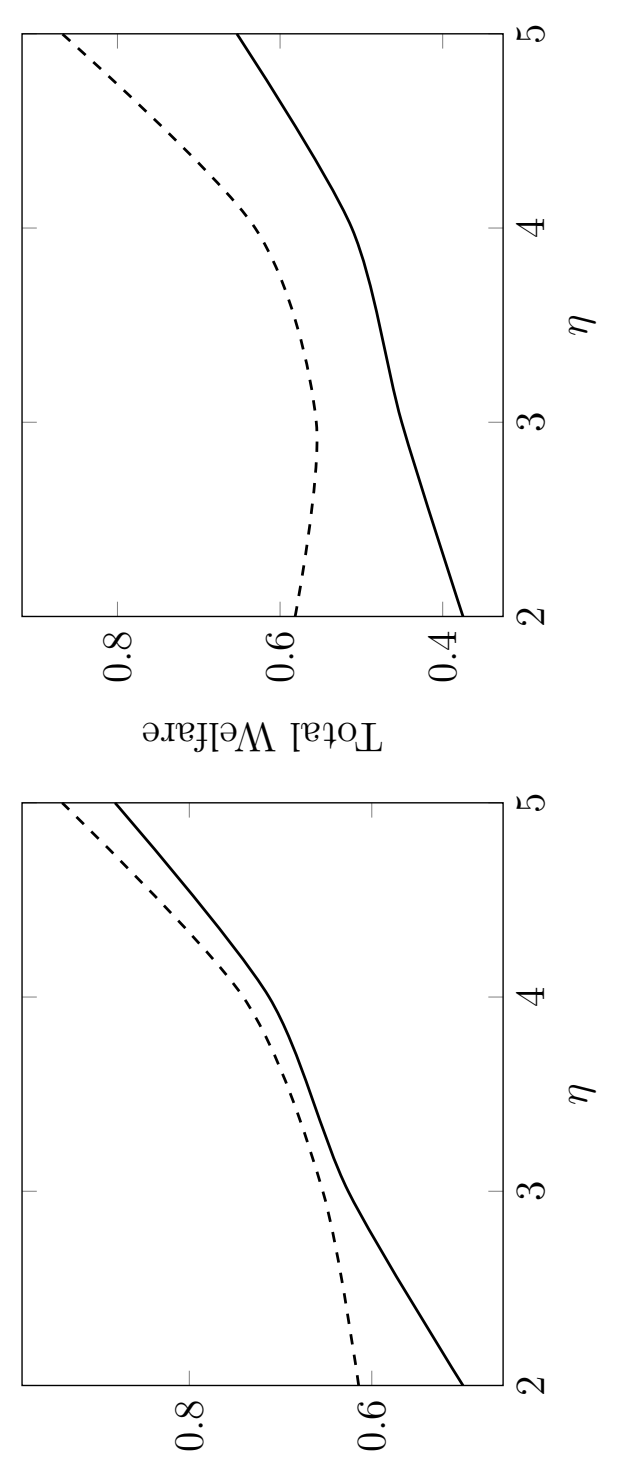

$\left({ }_{*}^{q_{\partial}}\right)$ длоШя шюәтұsuмо

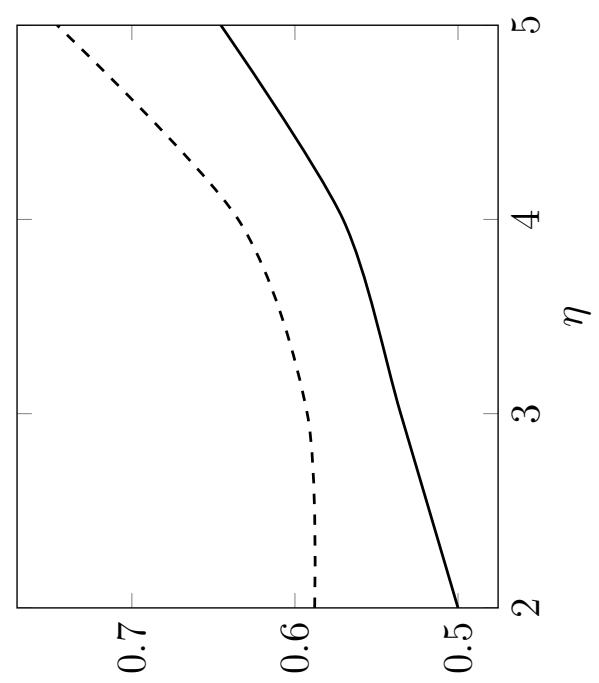

$\left({ }_{*}{ }^{2}\right)$ ᄀлошя шеәлұsd

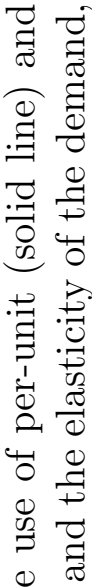

索

武:

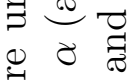

范 3.

苚

륭

式苍

굥 1

象:

घ

过

范苛识

完孚

용

$\rightarrow 0$

की

究

एँ

है

घี ॠ

要

है

它寻

$\div \frac{0}{0}$

我总告

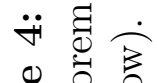

0 응

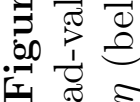


In order to understand the ex-ante incentives, however, we need to rely on numerical analysis. In Figures 3 and 4 we provide an example of the effects of the different parameters of the model over the equilibrium decisions in the first stage of the model, upstream and downstream effort, together with social welfare.

The results indicate that ad-valorem royalties translate into higher investment by upstream developers. This effect is particularly important for low values of $c$ and $\alpha$. In the case of the former, as in the one upstream innovator case, the result stems from the fact that the double-marginalization effect under ad-valorem royalties is small when $c$ is low, implying a large optimal royalty $s^{*}$ and large upstream profits which spur investment. For the latter, notice that low values of $\alpha$ imply that the investment of different upstream producers are more complementary. As a result, the higher profits that ad-valorem royalties imply are reinforced by the increased investment of other innovators.

In the case of the downstream producer the equilibrium effect on investment is the combination of two forces. On the one hand, ad-valorem royalties lead to lower downstream profits contingent on success, as illustrated in Proposition 4 , which feed back into lower incentives to invest. On the other hand, as mentioned in the previous paragraph, upstream innovators invest more and, under the complementarity of investments assumption, the marginal productivity of downstream investment raises. The results indicate that the second force typically dominates and downstream investment also raises under ad-valorem royalties. The only exception corresponds to the case in which $N_{U}<2$. From the previous section we know that under ad-valorem royalties when there is only one upstream developer downstream profits are lower and so are the incentives to innovate.

Total welfare is generally higher under ad-valorem royalties. This result arises due to two reasons. First, ad-valorem royalties lead to lower final prices, favoring consumers. Second, they typically generate an increase in total investment and in the resulting probability of product success. The difference in total surplus is particularly large when we 
consider more complementary upstream innovations.

\section{Downstream Competition}

We now analyze the opposite case to the one discussed in the previous section. We introduce downstream competition while assuming that, as in the benchmark model, there is a unique upstream developer. Consistent with the rest of the paper we assume that

downstream producer $i$ exerts effort $e_{D}^{i}$ at a cost $C\left(e_{D}^{i}\right)=\frac{\left(e_{D}^{i}\right)^{2}}{2}$. That effort in combination with upstream investment, leads to a probability $e_{U} e_{D}^{i}$ of technological success of the product of firm $i$.

Of course, when there are potentially multiple downstream producers, technological success does not immediately translate into market success. It depends on the technological success or failure of the competitors. In order to simplify the analysis we assume that all downstream firms, if successful, sell an identical product and compete in prices so that profits are 0 if more than one firm succeeds. Furthermore, in order to illustrate our results we focus our discussion on the case in which there are just two downstream producers, $N_{D}=2$.

In the first stage downstream producer $i=1,2$ chooses effort to maximize

$$
\max _{e_{D}^{i}} e_{U} e_{D}^{i}\left(1-e_{D}^{j}\right) \Pi_{D}+e_{D}^{i} \pi_{0}^{D}-\frac{\left(e_{D}^{i}\right)^{2}}{2},
$$

where $j \neq i$. The previous expression indicates that downstream producer $i$ only obtains profits from the production of the good when that firm and the upstream producer succeed while the downstream competitor fails. In that case, downstream profits, $\Pi_{D}$, are identical to those obtained in the benchmark case. Otherwise, profits arise only from the alternative uses of the innovation.

The upstream producer chooses effort to maximize

$$
\max _{e_{U}} e_{U} e_{D}^{1} e_{D}^{2} \Pi_{U}(2)+e_{U}\left[e_{D}^{1}\left(1-e_{D}^{2}\right)+\left(1-e_{D}^{1}\right) e_{D}^{2}\right] \Pi_{U}(1)+e_{U} \pi_{0}^{U}-\frac{e_{U}^{2}}{2} .
$$


The profits from royalties in the last stage of the game depend on the number of final good producers that end up competing in the market. When only one producer succeeds profits become $\Pi_{U}(1)$, identical to the profits in the benchmark model. Alternatively, when both downstream producers succeed upstream equilibrium profits, $\Pi_{U}(2)$, have a very simple expression arising from the following logic. Downstream Bertrand competition eliminates the double marginalization and, consequently, the price in the final market corresponds to the perceived marginal cost of each downstream producer $\left(c+r\right.$ and $\frac{c}{1-s}$ under perunit and ad-valorem royalties, respectively). For this reason, the upstream producer will find optimal to choose a royalty rate that induces the monopoly price downstream, $p^{M}=\frac{\eta}{\eta-1} c$. In this way, the upstream monopolist will obtain monopoly profits regardless of the royalty scheme used. These profits can be computed as

$$
\Pi_{U, p u}^{*}(2)=\Pi_{U, a v}^{*}(2)=\pi^{M}=\frac{(\eta-1)^{\eta-1}}{\eta^{\eta}} c^{1-\eta} .
$$

Incidentally, it is important to point out that it is only in this context of ex-post perfect competition that per-unit and ad-valorem royalties (and consequently the apportionment and the entire market value rule) are equivalent.

The previous maximizations characterize the symmetric equilibrium of the first stage - that is when all downstream producers choose the same investment level -, through the intersection of the reaction functions $H_{U}\left(e_{D}\right)$ and $H_{D}\left(e_{U}\right)$

$$
\begin{aligned}
& e_{U}^{*}=H_{U}\left(e_{D}^{*}\right)=\left(e_{D}^{*}\right)^{2} \pi^{M}+2\left(1-e_{D}^{*}\right) e_{D}^{*} \Pi_{U}+\pi_{0}^{U}, \\
& e_{D}^{*}=H_{D}\left(e_{U}^{*}\right)=\frac{e_{U}^{*} \Pi_{D}+\pi_{0}^{D}}{1+e_{U}^{*} \Pi_{D}} .
\end{aligned}
$$

for the upstream and downstream producers, respectively. It is easy to see that increases in $e_{D}$ always increase the investment incentives of the upstream producer. This result is due to the fact that increases in $e_{D}$ make the downstream duopoly case more likely and, thus, the returns from the investment upstream raise. In contrast, the effects of $e_{U}$ on downstream investment are the result of two opposing forces. On the one hand, 
increases in $e_{U}$ make technological success more likely and, due to the complementarity, the incentives to invest downstream increase. On the other hand, each downstream producer anticipates that the competitor might have more incentives to invest and monopoly profits will be less likely to arise. This second effect reduces the incentives to invest in the first place and it is more important the larger are the exogenous reasons to invest, $\pi_{0}^{D}$

The effects of $\Pi_{U}$ and $\Pi_{D}$ on investment can be described along the same lines. Whereas the direct effect of increases in $\Pi_{U}$ on $e_{U}^{*}$ is positive, increases in $\Pi_{D}$ generate two opposing effects for the reasons discussed above.

As in the case of multiple upstream innovators, it is difficult to have analytical results and, for this reason, we again rely on numerical simulations. Figure 5 shows how the effort of the upstream developer and downstream producers change when marginal cost and the elasticity of the demand vary under both per-unit and ad-valorem royalties.

The results indicate that, as expected and consistent with the rest of the paper, ad-valorem royalties in general spur the investment of the upstream developer whereas per-unit royalties provide more incentives for the downstream firms to invest. These differences become more significant when demand elasticity is low. Regarding costs, we observe that when the marginal cost is small ad-valorem royalties do not lead to significantly higher effort upstream while at the same time downstream effort is reduced. This result arises from the fact that when the marginal cost is low double marginalization is small under ad-valorem royalties, leading the upstream developer to charge a high royalty, which once anticipated discourages downstream investment. The complementarity between investments reduces the upstream incentives to innovate. The combination of both forces leads to lower welfare under ad-valorem royalties, due to the lower probability of success it entails.

When marginal costs increase, however, upstream effort becomes significantly higher 


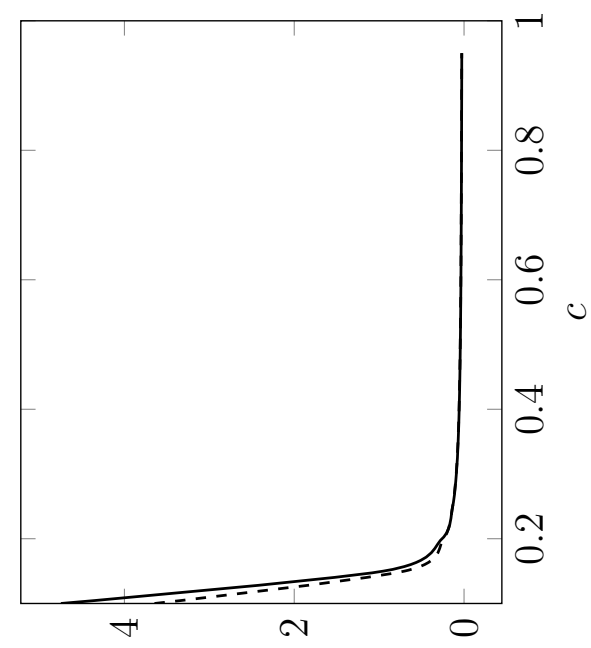

әлеләМ [РาоL

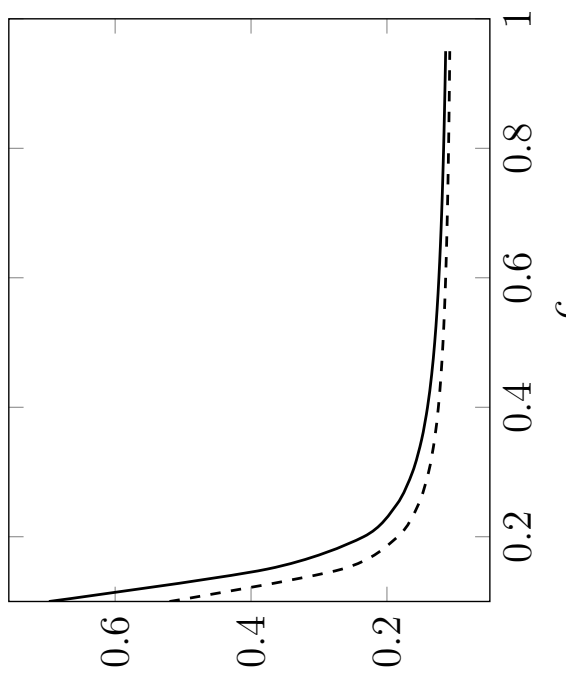

$\left({ }_{*}^{\circ}\right)$ ұлошя шеәлұsuмо

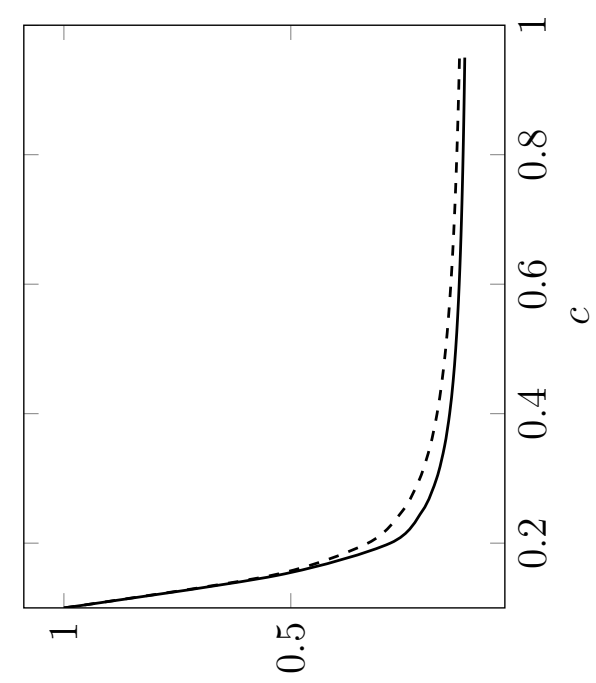

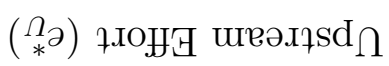

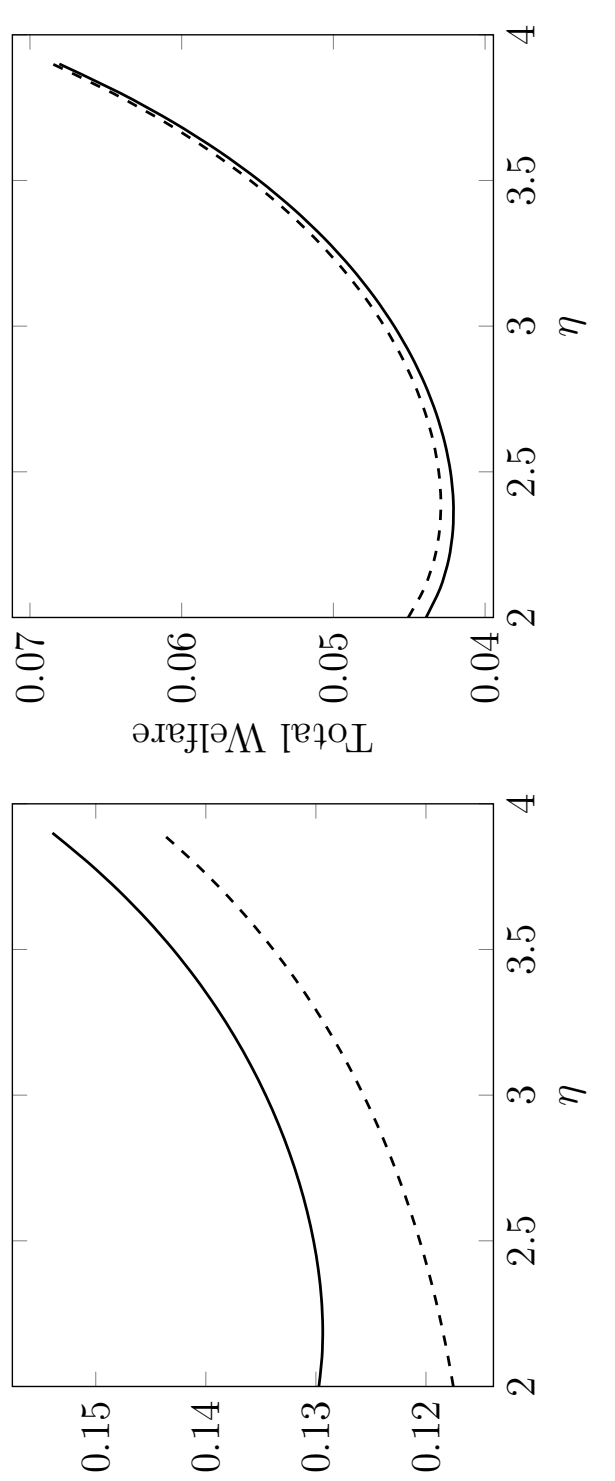

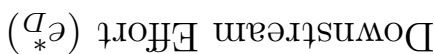

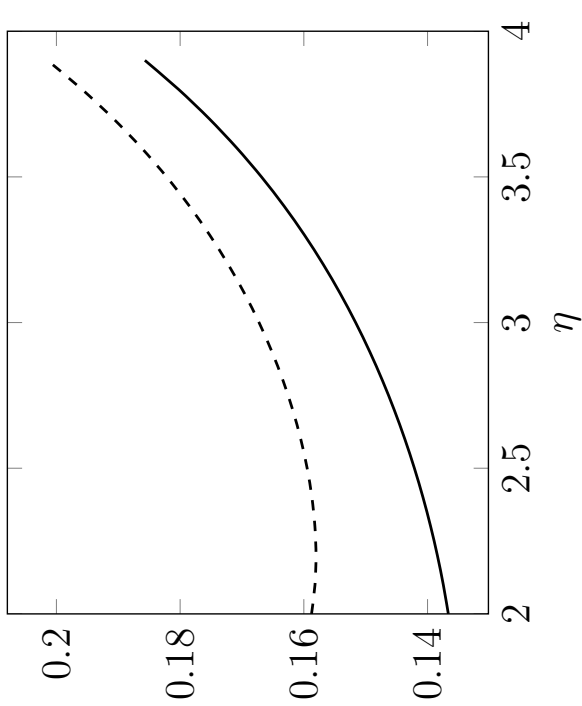

$\left({ }_{*}^{n}{ }^{2}\right)$ ㄱо벼 шеәлұsd $\Lambda$

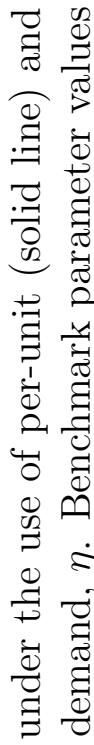

웅

营

$3 \cdot \overrightarrow{7}$

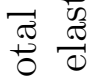

$\exists$

\%

क्ष ซี

d.

苛

药

코용

范

훙 of 11

焉最

ฮे

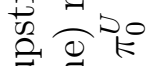

字寻 责

อ 휴

范表

虹胥

$\ddot{3}$ 퀑

范

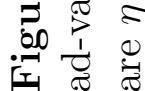


under ad-valorem royalties which compensates the lower investment by downstream producers due to their lower expected profits contingent on success. From the point of view of social welfare, ad-valorem royalties lead to higher total surplus only when marginal cost is large, although the magnitude of the difference in either direction is difficult to appreciate in the simulation. Thus, the implications of downstream competition are likely to be second order when compared to the impact of introducing other upstream producers or of considering other demand functions. In both cases, ad-valorem royalties are likely to be preferred as we saw in section 4 for the former and we will see in the next section for the latter.

\section{Concluding Remarks}

We have shown that, under most circumstances, royalties based on the value of sales - i.e. royalties where the scope of the royalty base is determined by the entire market value rule - yield superior outcomes from both consumer welfare and total welfare standpoints than per-unit royalty rates - i.e. royalties where the scope of the royalty base is determined by reference to the value of the components of the infringing product that are covered by the patented technology.

Our models abstract from implementation issues. When those are taken into account, the welfare superiority of the entire market value rule, and hence of the ad-valorem royalties, is only reinforced. In our analysis, ad-valorem royalties are better from the consumer welfare and total welfare perspectives for two reasons. First, the entire market value rule mitigates the double marginalization problem that naturally arises in technology markets characterized by market power at the licensing and manufacturing levels of the vertical chain. This is because licensors internalize the impact on the prices of the end products of an increase in their royalty rate to a greater extent when the royalty base is given by the entire market value of the product. Second, investments by both technology 
developers and implementers can be greater under the entire market value rule because overall industry profits, and hence the incentives to innovate, are greater when the double marginalization problem is less severe. This effect is stronger, and therefore the entire market value rule is even more attractive, when bargaining power is distributed between both parties or when there are multiple innovators licensing complementary technologies. Because ad-valorem royalties shift profits upstream, they compensate the tendency to underinvest by owners of complementary technologies.

Our results can be used to develop normative implications in the context of standard essential patents or SEPs. The findings of our benchmark model, in which patent holders own complementary patents, suggest that it would be wrong to mandate per-unit royalties for SEPs, as this would discourage innovation. To the extent that policy-makers are concerned about the possibility of patent hold up and royalty stacking, they should advocate in favor of the entire market value rule, as that is likely to result in greater consumer and social welfare.

The results of the model generalize to other forms of innovation. In Appendix B we allow for situations in which upstream innovations might be substitutes and, therefore, non-essential for the success of the product. We show that even in that case results are qualitatively unchanged. 


\section{References}

Bhattacharyya, Sugato and Francine Lafontaine, "Double-Sided Moral Hazard and the Nature of Share Contracts," The RAND Journal of Economics, 1995, 26(4), pp. $761-781$.

Bousquet, Alain, Helmuth Cremer, Marc Ivaldi and Michel Wolkowicz, "Risk sharing in licensing," International Journal of Industrial Organization, September 1998, 16(5), pp. 535-554.

Colombo, Stefano and Luigi Filippini, "Patent licensing with Bertrand competitors," DISCE - Quaderni dell'Istituto di Teoria Economica e Metodi Quantitativi itemq1262, Universit Cattolica del Sacro Cuore, Dipartimenti e Istituti di Scienze Economiche (DISCE), April 2012.

Gaudin, German And Alexander White, "Unit vs. Ad Valorem Taxes under Revenue Maximization," 2014, URL http://papers.ssrn.com/sol3/papers.cfm? abstract_id=2440708, mimeo.

Geradin, Damien and Anne Layne-Farrar, "Patent Value Apportionment Rules for Complex, Multi-Patent Products," Santa Clara Computer $\&$ High Technology Law Journal, 2011, 4(27), pp. 763-792.

Gilbert, Richard J. And Michael L. Katz, "Efficient Division of Profits from Complementary Innovations," International Journal of Industrial Organization, July 2011, 29(4), pp. 443-454.

Hernández-Murillo, Ruben and Gerard Llobet, "Patent licensing revisited: Heterogeneous firms and product differentiation," International Journal of Industrial Organization, January 2006, 24(1), pp. 149-175.

Holmstrom, Bengt, "Moral Hazard in Teams," Bell Journal of Economics, Autumn 1982, $13(2)$, pp. 324-340.

Kamien, Morton I. and Yair Tauman, "Fees Versus Royalties and the Private Value of a Patent," The Quarterly Journal of Economics, 1986, 101(3), pp. 471-492. 
Love, Brian J., "Patent Overcompensation and the Entire Market Value Rule," Stanford Law Review, 2007, 60(1), pp. 263-294.

Romano, Richard Evans, "Double Moral Hazard and Resale Price Maintenance," RAND Journal of Economics, 1994, 25(3), pp. 455-466.

Salop, Steven C. And David T. Scheffman, "Raising Rivals' Costs," The American Economic Review, 1983, $73(2)$, pp. 267-271.

San Martín, Marta And Ana I. Saracho, "Royalty licensing," Economics Letters, May 2010, 107(2), pp. 284-287.

Sherry, Edward F. And David J. Teece, "Some Economic Aspects of Intellectual Property Damages," PLI/PAT, 1999, 572, pp. 399-403.

Suits, D. B. And R. A. Musgrave, "Ad Valorem and Unit Taxes Compared," The Quarterly Journal of Economics, 1953, 67(4), pp. 598-604. 


\section{A Proofs}

Lemma A.1. A twice continuously differentiable profit function $\Pi(p)=(p-c) D(p)$ is quasiconcave if the elasticity of the demand $\eta(p)=-\frac{D^{\prime}(p) p}{D(p)}$ is increasing in $p$.

Proof of Lemma A.1: A single variable function $\Pi(p)$ is quasiconcave if (i) it is either always increasing or always decreasing in $p$ or (ii) if there exists a $p^{*}$ such that $\Pi(p)$ is increasing for $p<p^{*}$ and decreasing for $p>p^{*}$.

Let's assume, towards a contradiction that neither of the two previous conditions is true. In that case, at least one of the solutions to the first order condition must characterize a minimum. We now show that this cannot occur and there is at most one solution characterized by the first order condition which determine a maximum.

The Lerner index

$$
\frac{p^{*}-c}{p^{*}}=\frac{1}{\eta\left(p^{*}\right)}
$$

shows that there can be at most one solution, since the left-hand side is always increasing while the right hand side is always decreasing, when $\eta(p)$ is increasing in $p$.

We now show that this unique critical value $p^{*}$ always defines a maximum. In order to do that, notice that

$$
\frac{\partial \eta}{\partial p}=-\frac{D^{\prime}(p) D(p)+p D^{\prime \prime}(p) D(p)-D^{\prime}(p)^{2}}{D^{2}(p)} .
$$

This expression is positive if and only if

$$
D^{\prime \prime}(p) \leq \frac{D^{\prime}(p)^{2}}{D(p)}-\frac{D^{\prime}(p)}{p},
$$

We can now compute

$$
\Pi^{\prime \prime}\left(p^{*}\right)=D^{\prime \prime}\left(p^{*}\right)\left(p^{*}-c\right)+2 D^{\prime}\left(p^{*}\right)<D^{\prime}\left(p^{*}\right)\left(1-\frac{1}{\eta\left(p^{*}\right)}\right)=D^{\prime}\left(p^{*}\right) \frac{p^{*}-c}{p^{*}}<0,
$$

where first inequality comes from the upper bound on $D^{\prime \prime}(p)$ originating from the previous expression. Thus, the profit function is quasi-concave.

Lemma A.2. Assume that $D(p)$ is a twice-continuously differentiable demand function with a price elasticity $\eta(p)$ increasing in the price. Then, under per-unit royalties the optimal price has an upper bound

$$
p_{p u}^{*} \leq \frac{\left(c+r^{*}\right)^{2}}{c}
$$


Proof of Lemma A.2: Using Lerner's rule we have that under per-unit royalties the optimal price is determined as

$$
\left(1-\frac{1}{\eta\left(p_{p u}^{*}\right)}\right) p_{p u}^{*}=c+r
$$

where we have made explicit the dependency of the demand elasticity $\eta$ on $p$. Using the Implicit Function Theorem we have that

$$
\frac{\partial p_{p u}^{*}}{\partial r}=\frac{1}{\left(1-\frac{1}{\eta(p)}\right)+\frac{p}{\eta(p)^{2}} \eta^{\prime}(p)}>0 .
$$

In the first stage the upstream developer chooses the royalty to maximize $r D\left(p_{p u}^{*}(r)\right)$, resulting in a first order condition

$$
D\left(p_{p u}^{*}\left(r^{*}\right)\right)+r^{*} D^{\prime}\left(p_{p u}^{*}\left(r^{*}\right)\right) \frac{\partial p_{p u}^{*}}{\partial r}=0 .
$$

Solving for $r^{*}$ and after replacing (A.2) we have that

$$
r^{*}=-\frac{D\left(p_{p u}^{*}\left(r^{*}\right)\right)}{D^{\prime}\left(p_{p u}^{*}\left(r^{*}\right)\right) \frac{\partial p_{p u}^{*}}{\partial r}}=\frac{p_{p u}^{*}\left(1-\frac{1}{\eta\left(p_{p u}^{*}\right)}\right)+\frac{\left(p_{p u}^{*}\right)^{2}}{\eta\left(p_{p u}^{*}\right)^{2}} \eta^{\prime}\left(p_{p u}^{*}\right)}{\eta\left(p_{p u}^{*}\right)} .
$$

Substituting $r^{*}$ in A.1 , the first-order condition for the downstream producer, and rearranging terms we have

$$
\left(1-\frac{1}{\eta\left(p_{p u}^{*}\right)}\right)^{2} p_{p u}^{*}=c+\frac{\left(p_{p u}^{*}\right)^{2}}{\eta\left(p_{p u}^{*}\right)^{3}} \eta^{\prime}\left(p_{p u}^{*}\right) .
$$

We can now replace the left hand side expression by $\frac{(c+r)^{2}}{c p_{p u}^{*}}$ and rearrange terms to obtain

$$
p_{p u}^{*}=\frac{\left(c+r^{*}\right)^{2}}{c+\frac{\left(p_{p u}^{*}\right)^{2}}{\eta\left(p_{p u}^{*}\right)^{3}} \eta^{\prime}\left(p_{p u}^{*}\right)} \leq \frac{\left(c+r^{*}\right)^{2}}{c}
$$

where the last inequality arises from $\eta^{\prime}(p) \geq 0$.

Proof of Proposition 1: For the first part, take a per-unit royalty $r$. The profit maximizing price for the downstream producer satisfies

$$
\left(1-\frac{1}{\eta}\right) D\left(p_{p u}^{*}\right)=c+r
$$

whereas with ad-valorem royalties the same price could be reached with a royalty $s$ such that

$$
(1-s)\left(1-\frac{1}{\eta}\right) D\left(p_{a v}^{*}\right)=c
$$


Notice that to simplify notation we have dropped the argument in the demand elasticity $\eta$. From Lemma A.1 these first order conditions are necessary and sufficient.

It is immediate that the two royalties lead to the same price if and only if

$$
r=\frac{s}{1-s} c
$$

Upstream profits under per-unit royalties are

$$
\Pi_{U, p u}(r)=r D\left(p^{*}\right)=s \frac{c}{1-s} D\left(p^{*}\right)<s p^{*} D\left(p^{*}\right)=\Pi_{U, p u}(s),
$$

where the last inequality comes from the fact that $(1-s) p^{*}>c$

For the second part, take the optimal per-unit royalty $r^{*}$ and the equilibrium price $p_{p u}^{*}=p^{*}$. As shown before, this same price could be induced under an ad-valorem royalty $\hat{s}=\frac{r}{c+r}$. Given the concavity of the profits of the upstream producer it is enough to show that the derivative of the profits of the upstream producer evaluated at $\hat{s}$ is positive. In particular,

$$
\frac{\partial \Pi_{U, a v}}{\partial s}(\hat{s})=p^{*} D\left(p^{*}\right)+\hat{s}\left[p D^{\prime}\left(p^{*}\right)+D\left(p^{*}\right)\right] \frac{\partial p^{*}}{\partial s} .
$$

Using the Implicit Function Theorem on A.3 and A.4 and using the fact that under $\hat{s}$ the equilibrium price is the same we have that

$$
\frac{\partial p_{a v}^{*}}{\partial s}=\frac{\left(1-\frac{1}{\eta}\right) D\left(p^{*}\right)}{1-\hat{s}} \frac{\partial p^{*}}{\partial r}=\frac{c+r^{*}}{1-\hat{s}} \frac{\partial p^{*}}{\partial r} .
$$

Replacing in the previous first order condition together with the expression for $\hat{s}$ and the fact that $p^{*} D^{\prime}\left(p^{*}\right)+D\left(p^{*}\right)=(c+r) D^{\prime}\left(p^{*}\right)$ from the optimality of $p^{*}$ we have that

$$
\frac{\partial \prod_{U, a v}}{\partial s}(\hat{s})=p_{a v}^{*} D\left(p_{a v}^{*}\right)+\frac{r^{*}\left(c+r^{*}\right)^{2}}{c} D^{\prime}\left(p^{*}\right) \frac{\partial p^{*}}{\partial r} .
$$

Finally, notice that the first order condition that pins down $r^{*}$ implies that $D^{\prime}\left(p^{*}\right) \frac{\partial p^{*}}{\partial r}=$ $\frac{D\left(p^{*}\right)}{r^{*}}$ and replacing we have that

$$
\frac{\partial \Pi_{U, a v}}{\partial s}(\hat{s})=\left[p_{a v}^{*}-\frac{\left(c+r^{*}\right)^{2}}{c}\right] D\left(p_{a v}^{*}\right)<0
$$

where the last inequality comes from Lemma A.2.

Proof of Proposition 2: Given that prices in both cases are identical, $p_{a v}^{M}=p_{p u}^{M}=$ $p^{M}$ consumer surplus contingent on success is constant and can be written as

$$
C S \equiv \int_{p^{M}}^{\infty} p^{-\eta} d p .
$$


Consider a given level of profits for the upstream developer and downstream producer $\Pi_{U}$ and $\Pi_{D}$, respectively. The social welfare function can be written as

$$
W=e_{U}^{*} e_{D}^{*}\left(C S+\Pi_{U}+\Pi_{D}\right)+e_{U}^{*} \pi_{0}^{U}+e_{D}^{*} \pi_{0}^{D}-\frac{\left(e_{u}^{*}\right)^{2}}{2}-\frac{\left(e_{D}\right)^{2}}{2},
$$

where $e_{U}^{*}$ and $e_{D}^{*}$ can be obtained from (3) and (4). Given that $\Pi_{U, p u}^{*}+\Pi_{D, p u}^{*}=\Pi_{U, a v}^{*}+$ $\Pi_{D, a v}^{*}$ it is immediate that $C S+\Pi_{U}+\Pi_{D}$ is identical in both cases. Furthermore, equilibrium effort levels are the same if $\pi_{0}^{U}=\pi_{0}^{D}$, implying that the expected total surplus is the same under both kinds of royalties.

In order to show the result it is enough to show that $\frac{\partial W}{\partial \pi_{o}^{U}}$ is higher under per-unit royalties (and by symmetry $\frac{\partial W}{\partial \pi_{o}^{D}}$ is lower under ad-valorem royalties). This derivative can be computed as

$$
\frac{\partial W}{\partial \pi_{0}^{U}}=\frac{\pi_{0}^{D}\left(\Pi_{U} \Pi_{D}+1\right)+2 \pi_{0}^{U} \Pi_{D}}{\left(1-\Pi_{U} \Pi_{D}\right)^{2}} C S+\frac{\pi_{0}^{D}\left(\Pi_{U}+\Pi_{D}\right)+\Pi_{0}^{U}\left(\pi_{D}^{2}+1\right)}{\left(1-\Pi_{U} \Pi_{D}\right)^{2}} .
$$

It is easy to observe that since $\Pi_{U}+\Pi_{D}$ and $\Pi_{U} \Pi_{D}$ are constant under both kinds of royalty rates, the derivative will be higher in the case for which $\Pi_{D}$ is biggest. This corresponds to per-unit royalties.

Proof of Proposition 3: Immediate from the comparison of both prices.

Proof of Proposition 4: The ordering of the prices is immediate from their expressions. The inequality is strict when $N_{U}>1$.

Regarding profits, notice that

$$
\frac{\Pi_{D, p u}^{*}}{\Pi_{U, p u}^{*}}=\frac{\eta}{\eta-1}=\frac{\Pi_{U, a v}^{*}}{\Pi_{D, a v}^{*}}
$$

where $\frac{\eta}{\eta-1}>1$ proving the second part of the result. 


\section{B Other Upstream Complementarities}

The model in section 4 assumes that several upstream producers contribute complementary technologies. These technologies are perfectly complementary from the downstream producer point of view in the sense that all of them are required to be licensed for the product to be marketed. The technologies are less complementary in the development stage, and the higher is $\alpha$ the more independent these technologies become in that stage. In this section we study the implications of relaxing the previous assumption and assume that from the point of view of the downstream users technologies might not be perfectly complementary and, thus, not all of them might be required for the production of the good.

In particular, we assume that the marginal cost of the downstream producer is decreasing in the number of innovations licensed and takes the form $C(N)=c N^{-\beta}$ where $N \leq N_{U}$ is the number of technologies licensed and $\beta>0$. By varying the value of $\beta$ we can spawn different levels of downstream complementarity between innovations. A value of $\beta$ close to 0 makes the marginal cost independent of the number of innovations licensed, which implies that they become close substitutes. Larger values of $\beta$ increase the marginal valuation of additional innovations. When $\beta>1$ technologies essentially become complements, since the cost reduction is increasing in the number of technologies licensed.

\section{B.0.1 Per-Unit Royalties}

The monopoly price when the downstream producer has licensed $N$ innovations corresponds to $p^{*}(R, N)=\frac{\eta}{\eta-1}\left(c N^{-\beta}+R\right)$, where $R$ is the sum of all the royalties paid. Downstream producer profits can be written as

$$
\Pi_{D}(R, N)=\frac{(\eta-1)^{\eta-1}}{\eta^{\eta}}\left(c N^{-\beta}+R\right)^{1-\eta}
$$

Notice that in equilibrium all innovations must be licensed. Otherwise, left-out upstream producers would decrease the royalty rate in order to have their innovation licensed. In particular, let's consider the royalty rate of innovator $i, r_{i}$, when all other innovators have chosen a royalty $r$. The licensing decision can be obtained from the 
expression

$$
\begin{aligned}
& \max _{r_{i}} r_{i}\left(p^{M}\left(R, N_{U}\right)\right)^{-\eta} \\
& \text { s.t. } \Pi_{D}\left(R, N_{U}\right) \geq \Pi_{D}\left(R-r_{i}, N_{U}-1\right),
\end{aligned}
$$

where $R \equiv\left(N_{U}-1\right) r+r_{i}$ is the total royalty. The constraint indicates that the downstream producer will license the innovation if it leads to higher profits than if it licenses only $N_{U}-1$ technologies. This constraint can be rewritten as

$$
r_{i} \leq \bar{r} \equiv c\left[\left(N_{U}-1\right)^{-\beta}-N_{U}^{-\beta}\right]
$$

If the constraint is not binding the optimal royalty is identical to the one obtained in section 4. Thus, the royalties resulting from a symmetric equilibrium can be written as

$$
r^{*}=\min \left\{\frac{c N_{U}^{-\beta}}{\eta-N_{U}}, \bar{r}\right\}
$$

\section{B.0.2 Ad-Valorem Royalties}

The monopoly price under ad-valorem royalties when $N$ innovations are licensed can be written as $p^{*}(S, N)=\frac{\eta}{(1-S)(\eta-1)} c N^{-\beta}$, where $S$ is the total royalty paid. Replacing in the profit function of the downstream producer we obtain

$$
\Pi_{D}(S, N)=\frac{(\eta-1)^{\eta-1}}{\eta^{\eta}} \frac{\left(c N^{-\beta}\right)^{(1-\eta)}}{(1-S)^{-\eta}} .
$$

As in the previous case, all technologies will be licensed in equilibrium. We focus on a symmetric equilibrium, in which the optimal decision of innovator $i$ takes as given the royalty of all other innovators, $s$. In that case, $s_{i}$ results from the maximization

$$
\begin{aligned}
& \max _{s_{i}} s_{i}\left(p^{*}(S, N)\right)^{1-\eta} \\
& \text { s.t. } \Pi_{D}\left(S, N_{U}\right) \geq \Pi_{D}\left(\left(N_{U}-1\right) s, N_{U}-1\right) .
\end{aligned}
$$

where $S=\left(N_{U}-1\right) s+s_{i}$ is the total royalty. The previous constraint, which accounts for the fact that the downstream producer must prefer to license technology $i$ to using only the other ones, is satisfied if

$$
s_{i} \leq \bar{s} \equiv \frac{N_{U}^{-\beta(\eta-1) / \eta}-\left(N_{U}-1\right)^{-\beta(\eta-1) / \eta}}{\left(N_{U}-1\right) N_{U}^{-\beta(\eta-1) / \eta}-N_{U}\left(N_{U}-1\right)^{-\beta(\eta-1) / \eta}} .
$$



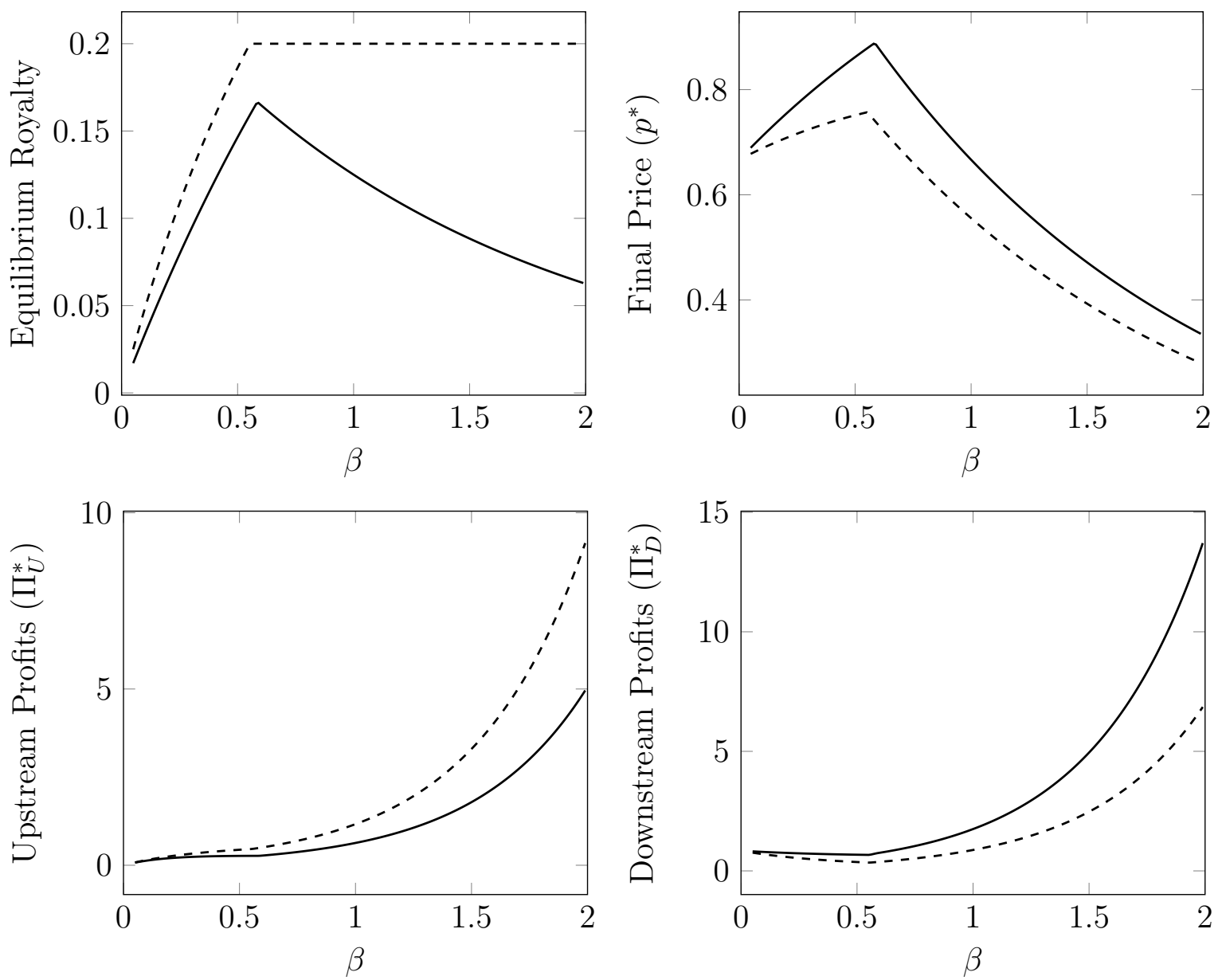

Figure 6: Equilibrium royalties, prices, and profits contingent on success of the innovation with per-unit (solid line) and ad-valorem (dashed line) royalties as a function of $\beta$. The remaining parameters are chosen as follows: $\eta=4, N_{U}=2$, and $c=0.5$.

The optimal royalty will correspond to the one that maximizes profits in section 4 when it is lower than the previous constraint or $\bar{s}$ otherwise. That is,

$$
s^{*}=\min \left\{\frac{1}{\eta+N_{U}-1}, \bar{s}\right\} .
$$

\section{B.0.3 Comparison}

Figure 6 provides a numerical example of the model for different values of $\beta$ both under per-unit and ad-valorem royalties. Regardless of the case, we can observe that the optimal royalty function is composed of two segments. When $\beta$ is low innovations are close substitutes. For this reason, the willingness to pay of downstream producers is low, forcing developers to ask for a low royalty that approaches 0 as innovations become closer to perfect substitutes. The functions $\bar{r}$ and $\bar{s}$ in equations (B.1) and (B.2) describe that 
region of values of $\beta$. When substitubility is low (or technologies become complements) the optimal royalty takes an interior value in the maximization, making the expression identical to the one obtained in the main part of the paper. Ad-valorem royalties become then independent of costs. Per-unit royalties are decreasing in $\beta$, since greater complementarity decreases costs, providing incentives for developers to charge lower royalties which benefit them through the increase in quantity produced.

The figure also shows that prices are higher under per-unit royalties, and this difference exists regardless of the level of complementarity between their innovations. This result reinforces Proposition 4 that showed this result for perfect complementarity. The shape of equilibrium prices responds to the evolution of royalty rates and the decrease in costs that higher values of $\beta$ entails. Higher royalty rates or higher costs are passed through higher prices.

Finally, profits display the same properties as those in our benchmark case. Under advalorem royalties upstream profits are higher whereas downstream profits are lower. These differences exist for all values of $\beta$ but they are particularly significant as innovations become more complementary. 


\section{CEMFI WORKING PAPERS}

0801 David Martinez-Miera and Rafael Repullo: "Does competition reduce the risk of bank failure?".

0802 Joan Llull: "The impact of immigration on productivity".

0803 Cristina López-Mayán: "Microeconometric analysis of residential water demand".

0804 Javier Mencía and Enrique Sentana: "Distributional tests in multivariate dynamic models with Normal and Student $t$ innovations".

0805 Javier Mencía and Enrique Sentana: "Multivariate location-scale mixtures of normals and mean-variance-skewness portfolio allocation".

0806 Dante Amengual and Enrique Sentana: "A comparison of mean-variance efficiency tests".

0807 Enrique Sentana: "The econometrics of mean-variance efficiency tests: A survey".

0808 Anne Layne-Farrar, Gerard Llobet and A. Jorge Padilla: "Are joint negotiations in standard setting "reasonably necessary"?".

0809 Rafael Repullo and Javier Suarez: "The procyclical effects of Basel II".

0810 Ildefonso Mendez: "Promoting permanent employment: Lessons from Spain".

0811 Ildefonso Mendez: "Intergenerational time transfers and internal migration: Accounting for low spatial mobility in Southern Europe".

0812 Francisco Maeso and Ildefonso Mendez: "The role of partnership status and expectations on the emancipation behaviour of Spanish graduates".

0813 Rubén Hernández-Murillo, Gerard Llobet and Roberto Fuentes: "Strategic online-banking adoption".

0901 Max Bruche and Javier Suarez: "The macroeconomics of money market freezes".

0902 Max Bruche: "Bankruptcy codes, liquidation timing, and debt valuation".

0903 Rafael Repullo, Jesús Saurina and Carlos Trucharte: "Mitigating the procyclicality of Basel II".

0904 Manuel Arellano and Stéphane Bonhomme: "Identifying distributional characteristics in random coefficients panel data models".

0905 Manuel Arellano, Lars Peter Hansen and Enrique Sentana: "Underidentification?".

0906 Stéphane Bonhomme and Ulrich Sauder: "Accounting for unobservables in comparing selective and comprehensive schooling".

0907 Roberto Serrano: "On Watson's non-forcing contracts and renegotiation".

0908 Roberto Serrano and Rajiv Vohra: "Multiplicity of mixed equilibria in mechanisms: a unified approach to exact and approximate implementation".

0909 Roland Pongou and Roberto Serrano: "A dynamic theory of fidelity networks with an application to the spread of HIV / AIDS".

0910 Josep Pijoan-Mas and Virginia Sánchez-Marcos: "Spain is different: Falling trends of inequality".

0911 Yusuke Kamishiro and Roberto Serrano: "Equilibrium blocking in large quasilinear economies".

0912 Gabriele Fiorentini and Enrique Sentana: "Dynamic specification tests for static factor models". 
0913 Javier Mencía and Enrique Sentana: "Valuation of VIX derivatives".

1001 Gerard Llobet and Javier Suarez: "Entrepreneurial innovation, patent protection and industry dynamics".

1002 Anne Layne-Farrar, Gerard Llobet and A. Jorge Padilla: "An economic take on patent licensing: Understanding the implications of the "first sale patent exhaustion" doctrine.

1003 Max Bruche and Gerard Llobet: "Walking wounded or living dead? Making banks foreclose bad loans".

1004 Francisco Peñaranda and Enrique Sentana: "A Unifying approach to the empirical evaluation of asset pricing models".

1005 Javier Suarez: "The Spanish crisis: Background and policy challenges".

1006 Enrique Moral-Benito: "Panel growth regressions with general predetermined variables: Likelihood-based estimation and Bayesian averaging".

1007 Laura Crespo and Pedro Mira: "Caregiving to elderly parents and employment status of European mature women".

1008 Enrique Moral-Benito: "Model averaging in economics".

1009 Samuel Bentolila, Pierre Cahuc, Juan J. Dolado and Thomas Le Barbanchon: "Two-tier labor markets in the Great Recession: France vs. Spain".

1010 Manuel García-Santana and Josep Pijoan-Mas: "Small Scale Reservation Laws and the misallocation of talent".

1101 Javier Díaz-Giménez and Josep Pijoan-Mas: "Flat tax reforms: Investment expensing and progressivity".

1102 Rafael Repullo and Jesús Saurina: "The countercyclical capital buffer of Basel III: A critical assessment".

1103 Luis García-Álvarez and Richard Luger: "Dynamic correlations, estimation risk, and portfolio management during the financial crisis".

1104 Alicia Barroso and Gerard Llobet: "Advertising and consumer awareness of new, differentiated products".

1105 Anatoli Segura and Javier Suarez: "Dynamic maturity transformation".

1106 Samuel Bentolila, Juan J. Dolado and Juan F. Jimeno: "Reforming an insideroutsider labor market: The Spanish experience".

1201 Dante Amengual, Gabriele Fiorentini and Enrique Sentana: "Sequential estimation of shape parameters in multivariate dynamic models".

1202 Rafael Repullo and Javier Suarez: "The procyclical effects of bank capital regulation".

1203 Anne Layne-Farrar, Gerard Llobet and Jorge Padilla: "Payments and participation: The incentives to join cooperative standard setting efforts".

1204 Manuel Garcia-Santana and Roberto Ramos: "Dissecting the size distribution of establishments across countries".

1205 Rafael Repullo: "Cyclical adjustment of capital requirements: A simple framework". 
1206 Enzo A. Cerletti and Josep Pijoan-Mas: "Durable goods, borrowing constraints and consumption insurance".

1207 Juan José Ganuza and Fernando Gomez: "Optional law for firms and consumers: An economic analysis of opting into the Common European Sales Law".

1208 Stéphane Bonhomme and Elena Manresa: "Grouped patterns of heterogeneity in panel data".

1209 Stéphane Bonhomme and Laura Hospido: "The cycle of earnings inequality: Evidence from Spanish Social Security data".

1210 Josep Pijoan-Mas and José-Víctor Ríos-Rull: "Heterogeneity in expected longevities".

1211 Gabriele Fiorentini and Enrique Sentana: "Tests for serial dependence in static, non-Gaussian factor models".

1301 Jorge De la Roca and Diego Puga: "Learning by working in big cities".

1302 Monica Martinez-Bravo: "The role of local officials in new democracies: Evidence from Indonesia".

1303 Max Bruche and Anatoli Segura: "Debt maturity and the liquidity of secondary debt markets".

1304 Laura Crespo, Borja López-Noval and Pedro Mira: "Compulsory schooling, education and mental health: New evidence from SHARELIFE".

1305 Lars Peter Hansen: "Challenges in identifying and measuring systemic risk".

1306 Gabriele Fiorentini and Enrique Sentana: "Dynamic specification tests for dynamic factor models".

1307 Diego Puga and Daniel Trefler: "International trade and institutional change: Medieval Venice's response to globalization".

1308 Gilles Duranton and Diego Puga: "The growth of cities".

1309 Roberto Ramos: "Banning US foreign bribery: Do US firms win?".

1310 Samuel Bentolila, Marcel Jansen, Gabriel Jiménez and Sonia Ruano: "When credit dries up: Job losses in the Great Recession".

1401 Felipe Carozzi and Luca Repetto: "Sending the pork home: Birth town bias in transfers to Italian municipalities".

1402 Anatoli Segura: "Why did sponsor banks rescue their SIVs? A signaling model of rescues".

1403 Rosario Crinò and Laura Ogliari: "Financial frictions, product quality, and international trade".

1404 Monica Martinez-Bravo: "Educate to lead? The local political economy effects of school construction in Indonesia".

1405 Pablo Lavado: "The effect of a child on female work when family planning may fail". 
1406 Gabriele Fiorentini and Enrique Sentana: "Neglected serial correlation tests in UCARIMA models".

1407 Julio Galvez and Javier Mencía: "Distributional linkages between European sovereign bond and bank asset returns".

1408 Laurent Clerc, Alexis Derviz, Caterina Mendicino, Stéphane Moyen, Kalin Nikolov, Livio Stracca, Javier Suarez and Alexandros P. Vardoulakis: "Capital regulation in a macroeconomic model with three layers of default".

1409 Gerard Llobet and Jorge Padilla: "The optimal scope of the royalty base in patent licensing". 